\title{
Design of regional and sustainable bio-based networks for electricity generation using a multi-objective MILP approach
}

\author{
Mar Pérez-Fortes ${ }^{\mathrm{a}, \mathrm{b}}$, José Miguel Laínez-Aguirre ${ }^{\mathrm{c}}$, Pol Arranz-Piera ${ }^{\mathrm{b}}$, Enrique Velo ${ }^{\mathrm{b}}$, Luis Puigjaner ${ }^{\mathrm{a}, *}$ \\ a Department of Chemical Engineering - CEPIMA, Universitat Politècnica de Catalunya (UPC-ETSEIB), Av. Diagonal 647, PG-2, 08028 Barcelona, Spain \\ ${ }^{\mathrm{b}}$ Institute of Sustainability, Science \& Technologies (IS), Universitat Politècnica de Catalunya (UPC), Pl. Eusebi Güell 6, 08034 Barcelona, Spain

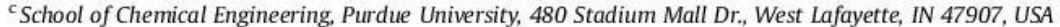

\begin{abstract}
A B S T R A C T
Biomass energy systems can be employed to meet the requirements of distributed energy systems in rural as well as urban contexts, whether this is an electrification or a microgeneration project. This work is focused on a mathematical programming approach applied to bio-based supply chains that use locally available biomass at or near the point of use in order to produce electricity or other bioproduct. The problem of designing and planning a regional biomass supply chain is formulated as a MO-MILP (multiobjective mixed integer linear program), which takes into account three main objectives: economic, environmental and social criteria. The model supports decision-making about location and capacity of technologies, connectivity between the supply entities, biomass storage periods, matter transportation and biomass utilisation. The advantages of this approach are highlighted by solving a case study of a specific district in Ghana. The aim is to determine the most suitable biomass and electricity network among the different communities. The technology considered to transform the biomass into electricity is gasification combined with a gas engine.
\end{abstract}

\section{Introduction}

The development of a successful bioenergy sector in both industrialised and developing countries will contribute to a longterm diversity, security and self-sufficiency of energy supply [1]. Current challenges emerging in the worldwide energy sector are consequence of diminution of natural sources, climate change and technology development. By adequately exploiting the resources and the available technologies, bioenergy is reckoned as (i) one of the most appreciated options to mitigate greenhouse gases emissions by replacing fossil fuels, (ii) an important resource in rural areas, and (iii) as a sustainable source of energy in vehicles and in electric power generation [2].

Biomass markets are changing from exclusively local to international markets. In this context, some regions are foreseen to become net exporters (e.g. Eastern Europe, Sub-Saharan Africa) and some other are potential importers (e.g. several members of the European Union, Japan) [3]. In order to create a stable market with biomass being a commodity, efficient networks to sustainable supply the amounts of biomass required, cost effective technologies

\footnotetext{
* Corresponding author. Tel.: +34 932451394.

E-mail addresses: mar.perez-fortes@upc.edu (M. Pérez-Fortes), luis.puigjaner@ upc.edu (L. Puigjaner).
}

to convert biomass, and improved distribution infrastructures to deliver the final product (i.e., energy or fuel) are to be developed [4]. Even more, the biomass market also implies a social dimension which needs appropriate regulations and policies to motivate its implementation, as well as new behaviour patterns [5]. To face these challenges, biomass sector practitioners should have available tools to guide the energy sector transformation in industrialised and developing countries. Additionally, such tools should integrate sustainability criteria to support the decision-making process. In this context, a SC (supply chain) modelling approach provides the framework to adequately exploit biomass for energy purposes and to properly assess the trade-off among different contrasting metrics and different biomass sources usages.

SCM (Supply chain management) deals with the coordination of materials, cash and information flows along the different processes in order to deliver efficiently goods or services. The processes and SC components can be geographically distributed. This is especially important for biomass to energy projects, that can be highly geographically dependent and their profitability can be strongly influenced by the location of the different processes and biomass sources. Indeed, it is widely recognised that logistic variables are of special complexity in this sort of projects [6]. Commonly, biomass production and transportation account for a significant fraction of the whole bioenergy SC cost [7]. SC modelling provides a tool 
capable of evaluating the trade-offs between the different potential locations for processing and consumption sites, and the different feedstock sources and their specific properties, i.e. moisture content, energy and bulk densities, which as previously stated, is a requisite to develop efficient bioenergy networks.

With regard to the performance evaluation, the implementation of a framework that considers the different realms of sustainability, is a challenge. This calls for a multiple-objective optimisation approach which should include economic, environmental and social criteria. Among them, the social or societal criterion is the less studied. Many rural projects traduce the social factor to exclusively job generation $[8,9]$. The work by [10] defines a social function based on employment and liveability. Nidumolu et al. [11] include the maximisation of food production as a surrogate criterion. The papers by [12] and [13] describe a methodology to determine the societal LCA (life cycle assessment), aiming to define a standard parameter. Job creation, local/national recruitment, generation of employment and conditions of work are some of the issues to be evaluated in this societal LCA. Note that social concerns in industrialised and developing countries can involve completely different aspects, ranging from security patterns to satisfaction of basic needs [14].

\subsection{Distributed energy systems}

Biomass as energy source has intrinsic characteristics that derive into technological limitations. Consequently, $100 \%$ biomass to energy projects employ small scale conversion systems which are generally placed close to the biomass generation source and/or to the demand points. This is to avoid logistic costs associated with the typical low energy densities and high volumes of biomass $[6,15,16]$. Bouffard and Kirschen [17] point out that the electricity generation sector will have to combine the best attributes of both paradigms, decentralised biomass conversion systems and large power plants with biomass co-used with fossil fuels.

Centralised energy systems consist in large power plants that export electricity to the grid and transport the raw material or energy source to the plant, while decentralised or DES (distributed energy systems) entail localised electricity generation near the demand points and near the biomass generation places. The conditions of the region makes either option advisable. No agreement exists in the literature about the definition of distributed generation, nevertheless it is usually perceived as small scale electricity generation [18]. The reviews of [19] and [18] point out that the term can be referred to (i) stand alone applications, (ii) standby sources that supply power during grid outages, (iii) cogeneration or waste heat recovery installations with power injection to the grid, (iv) DES that support the grid by decreasing power losses and improving the system voltage profile, and (v) energy systems connected directly to the grid that sell the electricity produced. This work considers DES as stand alone applications. Decentralised energy projects in development contexts are characterised by a lack of an integrated approach in rural electrification planning [9]. This has motivated the use of operations research to elucidate sustainable renewable energy approaches. For instance, [9] evaluates different technological options through goal programming to assess a qualitative response with respect to electricity generation cost, employment generation, avoided emissions and land use. Silva and Nakata [20] use LP (linear programming) to deal with the energy planning, finding financially sustainable solutions that appropiately connect sources and clients, and considers reliable income levels and energy demands. The subsidised costs are minimised. The paper suggests that the proliferation of renewable sources should be derived from environmental policies. Kanasse-Patil et al. [21] also employ an LP formulation to assure a reliable integrated renewable energy system by evaluating the cost of the energy, the costumer interruption costs, and the expected energy not supplied. The paper by [22] takes into account a large number of state-of-the-art evaluating parameters which are used for decentralised energy planning. Goal programming is employed using cost, system efficiency, petroleum products usage, locally available resources, employment generation, emissions and reliability on renewable energy systems as objective functions. The results show that, in the considered context, biomass-based systems have the potential to meet rural needs. Furthermore, they offer reliability, promote local participation, local control and create skills. The works by [23] and [24] develop, describe and use a multi-criteria decision tool called SURE, that is set to choose the appropriate energy mix of technologies to match the energy demand of a rural area. The tool combines quantitative and qualitative parameters and allows for changes on the priorities according to the decision-maker criteria. It is pointed out that technology assessment methods should be further developed to formulate more appropriated implementation strategies. The paper by [25] is an example of a modular renewable energy source implementation. It takes into account the results of a MILP approach that optimise the location of wind generators and selects the appropriate microgrid extension by minimising the investment costs. The approach for electricity generation through forest, fossil and wood-waste fuels described in [26] proposes a dynamic model to take operational decisions related to the biomass seasonality and availability. The interrupted availability of agricultural products has driven to an uncertainty treatment with a process graphs method [27].

The present work is specially focused on regional biomass SC. There are different works dealing with this topic in the literature, for instance [28] and [29]. In these cases, clusters and zones of competition and co-operation are determined using spatial planning and LP. Fisher and Pigneri [30] identify potential feedstock supply sites and specific areas of electricity demand with geographic matching, evaluating the levelised cost of the energy. It is pointed out that techno-economic and social-institutional factors are critical in regional problems. Silva and Nakata [31] introduce the concept of regional disparity to distinguish among three possible situations: urban, rural and remote areas. Urban areas are defined as large cities; rural and remote areas concern small towns and dispersed population, whether or not connection to the grid is available.

\subsection{Small scale gasification}

Biomass can be transformed into a gas, by means of digestion or gasification; into a liquid through fast pyrolysis, or directly combusted as a solid. In this paper, gasification is the chosen technological option to provide a combustible gas. According to [2], large gasification systems are from $10 \mathrm{MW}_{t h}$, while small gasification systems cover the range from less than $100 \mathrm{~kW}$ th up to a few $\mathrm{MW}_{\text {th }}$. In terms of electricity and in accordance with [32], small scale gasification plants enclose plants up to $200 \mathrm{~kW}_{e}$.

Small scale gasification systems are used to meet the specific requirements of DES using the available biomass, or pre-treated biomass, such as pellets, bought from an established market. Gasification systems have to overcome several issues before being a well extended technology. Lessons learned from real experiencies reflect the need of improving the technology and enhancing economic efficiencies, as well as finding appropriate application domains. There is a lack of well trained technicians in the field and of monitoring and evaluation programs of biomass gasification at small scale plants. There is also a lack of focus and proper impetus in such a projects. Current challenges on small scale gasification plants are raw material characterisation and homogenisation, improved gasification operation results (concerning tars and producer gas 
composition), more efficient cleaning units and an overall optimal performance [33]. Nevertheless [34], describes how small scale biomass gasification has been successful in a few niche markets.

The case study of this paper exemplifies a rural electrification problem. It tackles the strategic-tactical problem associated to the optimal design and operation of a BSC (bio-based supply chain) using a multi-objective mixed integer linear program (MO-MILP). The MILP approach captures the relevant fixed and variable operating costs for each facility and each major product [35] considering equipment allocation. The SC problem defined includes a specific region, understanding region as a delimited area where selfsufficient resources and clients are embraced. The gasification system is linked to an internal combustion engine (G-ICE) to produce electricity. This approach differs from the previous works in the consideration of biomass properties changes along the SC, as well as in the evaluation of economic, environmental and social trade-offs, aiming to propose sustainable solutions in time, far from the usual cooperative solutions proposed for rural electrification projects in developing countries.

\section{The bio-based supply chain}

This paper proposes a BSC based on two blocks: the biomass and the energy blocks. The first one comprises sourcing, biomass pretreatment and raw matter transportation, while the second one considers product generation and distribution. The sequence of pre-treatment, storage and transportation may change depending on the biomass type, the specific case study conditions and the chosen supply strategy.

Special features that distinguish a BSC from a conventional SC problem are: the use of multiple biomass sources from different origins that are geographically distributed, and the subsequent pretreatment required to homogenise the material in mass and energy terms. These features imply the combination of different MC (moisture contents), DM (dry matters), LHV (lower heating values) and BD (bulk densities). Biomass, with high MC, low BD, low LHV and fibrous nature, may lead to biomass pre-treatment so as to optimise its transport, handling and processing. Biomass properties can change along the SC, even if it is not the desired effect. The abovementioned biomass attributes are characterised in the SC model presented herein.

The major steps in the BSC are described as follows:

- Biomass growing, harvesting and collecting involve biomass production, by recovering biomass waste or using energy crops. Processes included here are drying, i.e. natural drying in the land field, baling or chipping. The two latter processes are used to diminish the volume and reduce the risk of deterioration [36]. Resource seasonality determines the harvesting or collection period. Different seasonal sources mix and storage could mitigate the impact on supply continuity.

- Biomass pre-treatment includes all the necessary steps to produce an upgraded fuel. Such a fuel is homogeneous, has no impurities and is denser in terms of mass and energy. Pretreatment allows costs reduction in biomass treatment, storage and transportation. Briquetting, pelletisation, torrefaction, pyrolysis, and combinations of them, are pre-treatment techniques [3]. Research in biomass pre-treatment is crucial for the large scale biomass market. In this line, [7] contemplate forest wood residues to produce torrified wood that supplies gasification units to produce electricity. Magalhaes et al. [37] evaluate prices, yields, distances, investment and operation costs of torrefaction and fast pyrolysis in a real case study that uses imported biomass. The paper by [38] evaluates the SC of bioslurry, a mixture of bio-oil and biochar, through the trade- off between the investment cost of distributed pyrolysis units and the reduced operation costs due to a denser biomass.

- Storage can be considered throughout the BSC. Biomass can be stored whether before the transportation stage, at the biomass origin, in an intermediate step or at the power station site. This is crucial to create backups against seasonality. A drying phenomenon takes place here, even some dry matter loss may occur [39]. Costs depend on the location and type of storage, i.e. open air, roof covered, air fan, indoor storage. Their selection depends on climate conditions, shape and volume of biomass and time of storage [16]. The work by [39] emphasizes the multi-biomass seasonal availability combined with the biomass storage problem.

- Transportation can be expensive due to the biomass low energy density. Costs depend on distance, speed, tortuosity, hauliers capacity and amount of biomass to be transported. Operating costs such as driver remuneration or fuel consumption, as well as social and environmental impacts should be evaluated [16]. Forsberg [40] analyses the transportation problem in terms of environmental viability and ecological sustainability. It considers the utilisation of trailer, truck, train, ship or pipeline, thus implying different biomass states and different distances to cover. Optimisation of this activity implies to find the appropriate match between the amount of disposable biomass near the plant and the plant size. Yu et al. [41] evaluate a malle residues SC focused on transportation costs. It results that onfarm transportation for central biomass gathering, can be more expensive than biomass road transportation due to the elevated costs derived from the feedstock collection area. The papers by [42] and [43] compare the transportation of bio-oil by pipeline or by truck through an LCA. The results depend on the distance to be covered and the source of energy consumed to pump the bio-oil or to run the trucks. Depending on the scale, transportation could represent the bottleneck of the BSC.

- Biomass treatment refers to the biomass-processing plant to produce the desired product, i.e. biofuels, bioproducts, heat, cool or electricity. Multi-products can be also considered, as in [44].

\section{Problem statement}

The design-planning of a BSC may require a highly applicationspecific or tailor-made approach [45]. The optimal SC specifically fulfills the needs of the target market; thus it is not possible to scale-up the proposed solution to address a different problem.

\subsection{Inputs}

\section{Process data}

- A set of materials; raw matter, intermediates and final products.

- A set of demands.

- A proposal of biomass pre-treatments and treatment technologies characterised by their efficiency. Consequently, a set of biomass materials as raw, pre-processed and processed matter, depicted by their main properties, are determined accordingly.

- A set of providers, intermediates and consumers locations.

- A time horizon.

2 Economic data

- An interest rate.

- Investment, fixed and variable costs associated with all the technological options involved.

- Products and consumables prices. 
3 Environmental data

- Raw material production environmental interventions.

- Each process environmental interventions.

- Transportation environmental interventions.

4 Social data

- Number of communities and number of potential processes to be installed in each community.

\subsection{Outputs}

1. The most suitable pre-processing units, with their corresponding capacity and location.

2. Connections between providers, intermediates and consumers.

3. Biomass storage periods.

4. Matter transportation flows.

5. Biomass utilisation.

6. The detail of the economic parameters and environmental impacts for each SC echelon.

The chosen objective functions should represent the decisionmaker interests. The metrics considered in this work include the three branches of sustainability.

- Net present value (NPV) as the economic metric.

- An LCA is performed for the environmental issues.

- The creation of jobs in the widest range of communities as the social indicator.

\section{Mathematical model}

A general outline of the BSC is shown in Fig. 1. It contemplates the activities described in Section 2: sourcing, pre-treatment, product generation and product distribution.

The BSC is defined as a number of potential locations where processing sites or distribution centres, or both of them can be installed. Suppliers are at fixed locations where biomass is available. The final product can be produced at several sites. The properties of the raw biomass may be enhanced by means of the pretreatment units so as to allow intermediates to meet the characteristics required by subsequent steps in the SC. Pre-treatments may be also convenient for reducing transportation costs. The production capacity of each processing site is modelled by relating the nominal production rate per activity to the availability of the equipment per year (i.e. the number of working hours per year and equipment). Storage and transportation activities are modelled by considering upper and lower bounds based on their corresponding biomass handling capacity. Distribution centres can be supplied from more than one pre-treatment plant or supplier. Materials flow between facilities may appear if selecting such a flow improves the performance of the SC. The market demand of electricity can be satisfied by more than one site.

All the abovementioned decisions will be taken by considering the optimisation of an economic (NPV), an environmental impact (Impact 2002+) and a social metric (SoC) along a pre-defined planning horizon.

Next, the mathematical formulation is described. The resulting model is solved by using an MO-MILP technique, specifically the $\varepsilon$-constraint method. Multi-objective optimisation allows assessing the trade-off among the economic, the environmental impact and the social indicator. The model variables and constraints can be categorised into four groups: (i) process operations constraints given by the design-planning sub-model, (ii) the economic metric formulation, (iii) the environmental sub-model and (iv) the surrogate social metric.

\subsection{Design-planning model}

The design-planning model selected to deal with the BSC network is adapted from the work of [46]. This model translates the State-Task-Network (STN) formulation [47], which is a widely known approach for scheduling, to the SC context. This SC designplanning formulation can collect all the SC nodes activities information through a single variable set. On the one hand, this feature eases the economic and environmental metrics formulation. On the other hand, it facilitates the consideration of pre-treatment activities and their outputs. The SC material balances can be modelled by means of a single equation set for all materials and echelons. This is possible since manufacturing nodes and distribution centres, as well as final products, raw material and intermediates are treated indistinctively. Therefore, the most relevant variable of the model is $P_{\text {iiff't }}[\mathrm{kg}$, which represents the magnitude of a particular task $i$, performed using technology $j$ during period $t$, whose origin is location $f$ and destination is location $f^{\prime}$. In the case of production activities, they must receive and deliver material within the same site $\left(P_{\text {ijfft }}\right)$. In contrast, in a distribution activity, facilities $f$ and $f^{\prime}$ must be different. This mathematical formulation assumes that an activity consumes and produces certain materials with determined properties and can be performed in different equipment. Using the activities as the core of the formulation rather than products-

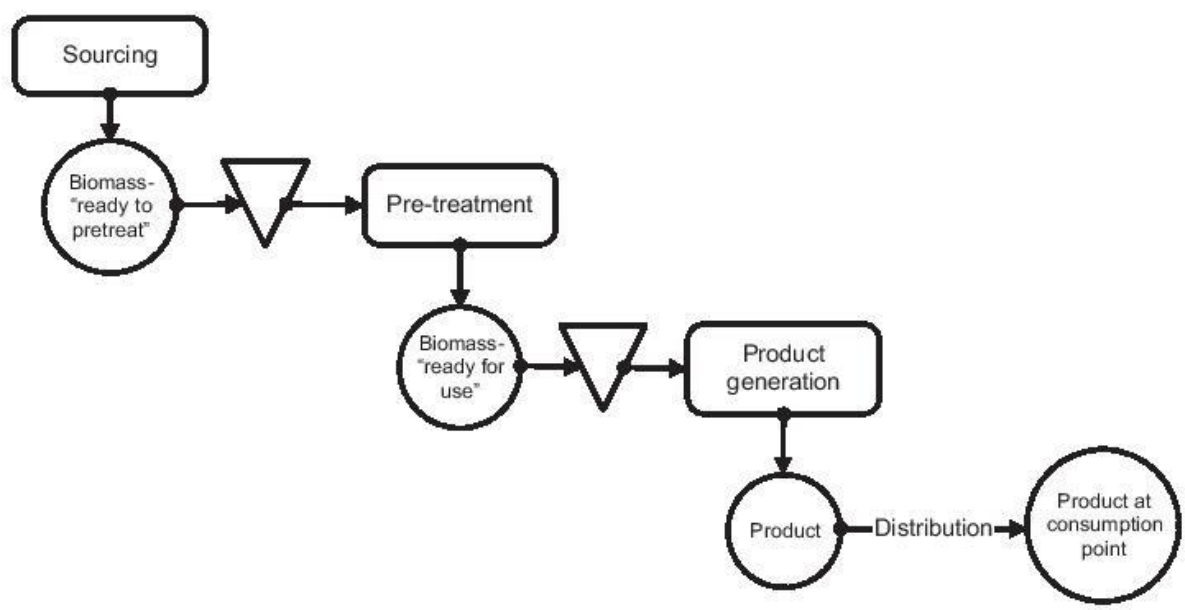

Fig. 1. General scheme considered here for a BSC. 
materials renders a flexible formulation which can be easily extended to deal with different case studies. The equations comprising this formulation are described in the following paragraphs.

Mass balance must be satisfied at each node of the network. The expression for the mass balance for each type of material $s$ (raw material, pre-processed biomass, final product) processed at each potential site $f$ in every time period $t$ is presented in Eq. (1). Parameter $\alpha_{\text {sij }}$ [adim.] is defined as the mass fraction of material $s$ that is produced by task $i$ using technology $j . T_{S}$ is a set that refers to tasks that produce $s$, while $\bar{\alpha}_{s i j}$ and $\bar{T}_{s}$ sets, are associated with tasks which consume $s$.

$$
\begin{aligned}
S_{s f t}-S_{s f t-1}= & \sum_{f^{\prime}} \sum_{i \in T_{s} \in} \sum_{\left(J_{i} \cap \tilde{J}_{f^{\prime}}\right)} \alpha_{s i j} P_{i j f f^{\prime} f t} \\
& -\sum_{f^{\prime}} \sum_{i \in \bar{T}_{s j \in}} \sum_{\left(J_{i} \cap \tilde{j}_{f}\right)} \bar{\alpha}_{s i j} P_{i j f f^{\prime} t} \forall s, f, t
\end{aligned}
$$

The change in inventory of material $s$ for consecutive planning periods and for each location is given by the difference between the amount of material produced by those tasks belonging to set $T_{\mathrm{S}}$ and the amount consumed by those tasks included in set $\bar{T}_{s}$. The model assumes that process parameters such as conversions, separation factors or temperatures, are fixed for each activity in order to enforce the linearity of the problem. In this sense, the parameters $\alpha_{s i j}$ [adim.] and $\bar{\alpha}_{s i j}$ [adim.] give the "recipe" for a specific activity. Nevertheless, there are activities $(\bar{I})$ for which it is desirable to let the model specify the mixture of inputs in order to achieve a given value of a specific biomass property, for instance, a specific moisture content. For such activities, the combination of feedstocks and, therefore, the proportion of each feedstock is variable. In order to take into account such activities, the mass balance is modified as shown in Eq. (2). Note that Eq. (1) is a particular case of Eq. (2)

$$
\begin{aligned}
S_{s f t}-S_{s f t-1}= & \sum_{f^{\prime}} \sum_{i \in T_{s}} \sum_{j \in(} \alpha_{\left(J_{i} \cap \tilde{J}_{f^{\prime}}\right)} \alpha_{s i j} P_{i j f^{\prime} f t}-\sum_{f^{\prime}} \sum_{i \in \bar{T}_{s}} \sum_{j \in\left(J_{i} \cap \tilde{J}_{f}\right)} \bar{\alpha}_{s i j} P_{i j f f^{\prime} t} \\
& +\sum_{i \in\left(T_{s} \cap \bar{l}\right)} \sum_{j \in\left(J_{i} \cap \tilde{J}_{f^{\prime}}\right)} P v_{s i j f t} \\
& -\sum_{i \in\left(\bar{T}_{s} \cap \bar{l}\right)} \sum_{j \in\left(J_{i} \cap \tilde{J}_{f^{\prime}}\right)} P v_{s i j f t} \forall s, f, t
\end{aligned}
$$

With regard to the variables $P_{\text {iiff't }}[\mathrm{kg}]$ and $P v_{\text {sif }} t[\mathrm{~kg}]$, notice that the former is used in the mass balance (Eq. (2)) coupled with the parameter $\alpha_{s i j}$ or $\bar{\alpha}_{s i j}$ which specify a fixed proportion of material produced or consumed for a task $i$. On the other hand, $P v_{\text {siff }}$ is modelling flexible tasks which allow the proportion of the material produced or consumed to vary so as to provide more alternatives for biomass mixing to the model. For this reason, $P v_{\text {sijft }}$ is not multipled by such parameters in Eq. (2).

For the activities for which biomass properties are fixed, the energy balance is satisfied directly by the definition of the streams. However, it is necessary to verify that the energy balance is satisfied for the flexible activities $(\bar{I})$. The energy balance for such activities is represented by Eq. (3). Here, $H V_{S}[\mathrm{MJ} / \mathrm{kg}]$ is the heating value of material s. Notice that each different type of biomass has a different heating value. A specific activity changes the heating value of the output stream if (i) it is a pre-treatment task that modifies explicitly the calorific value of the biomass, or (ii) it is a task whose main objective is the change of shape, but it is receiving a mixture of biomasses as input.

$$
\sum_{s \in T_{s}} H V_{s} P v_{s i j f t}=\sum_{s \in \bar{T}_{s}} H V_{s} P v_{\text {sijft }} \quad \forall i \in \bar{I}, j, f, t
$$

In case the flexible activities must accomplish an MC for the input stream, constraint (4) must be satisfied. The parameters Water $r_{s}$ [adim.] and Water ${ }_{i j}^{\max }$ [adim.] represent the MC for material $s$, and the maximum MC allowed for task $i$ performed in equipment $j$, respectively.

$$
\sum_{s \in S_{i}} \text { Water }_{s} P v_{\text {sijft }} \leq \text { Water }_{i j}^{\max } \sum_{s \in \bar{S}_{i}} P v_{\text {sijf't }} \quad \forall i \in \bar{I}, j, f, t
$$

Another important extension of this model is the consideration that storage is capable of changing biomass properties (e.g., moisture content, dry matter, heating value). In order to do so, storage should be considered as an actual activity. Let us define the subsets $J_{\text {stor }}$ and $S_{\text {stor }}$ which will represent the storage "equipment" and those materials that when kept in storage change their properties, respectively. Notice that the mass balance has been decomposed in this case so as to deal with the one period delay necessary for the properties change to occur. As expressed by Eqs. (5) and (6), a storage activity places inventory in the current period $t$ and takes inventory from the previous period $t-1$.

$$
\begin{aligned}
& S_{s f t}=\sum_{f^{\prime}} \sum_{i \in T_{s}} \sum_{j \in\left(J_{i} \cap \tilde{j}_{f^{\prime}} \cap J_{s t o r}\right)} \alpha_{s i j} P_{i j f^{\prime} f t} \quad \forall s \in S_{s t o r}, f, t \\
& S_{s f t-1}=\sum_{f^{\prime}} \sum_{i \in \bar{T}_{s}} \sum_{j \in\left(J_{i} \cap \tilde{J}_{f} \cap J_{s t o r}\right)} \bar{\alpha}_{s i j} P_{i j f f^{\prime} t} \quad \forall s \in S_{s t o r}, f, t
\end{aligned}
$$

We should point out that an important limitation of this modelling approach is that Eqs. (2)-(3) allow combining different materials in proportions which are defined by the optimisation just for the activity which performs the energy generation. The states feeding any other activity and their corresponding proportions and properties (e.g. MC, DM, BD, LHV) must be defined a priori. This implies that no combinations of different biomass are allowed before storage or such combinations must be also defined a priori.

Eqs. (7) and (8) represent the temporal change in the equipment technology installed in the potential facility locations. We will considered economies of scale by using a piecewise linear approximation in $K$ different intervals and a so-called SOS2 variable type $\left(\xi_{j f k}\right)$. Such variables are positive and at most two consecutive variables are non-zero. $F E_{j f k}^{\text {limit }}[\mathrm{h}]$ is the limit of capacity for interval $k$. $V_{\text {jft }}$ is a binary variable indicating whether or not capacity of technology $j$ is expanded at site $f$ in period $t$. This formulation will be recalled in the economic performance metric section for computing the investments associated with capacity expansions. Eq. (9) is used for the total capacity $F_{j f t}[\mathrm{~h}]$ bookkeeping taking into account the capacity augment during the planning period $t\left(F E_{j f t}\right.$ [h]) for equipment technology $j$ in facility $f$. This equation considers the case of the initial design of an $\mathrm{SC}\left(F E_{i f 0}=0\right)$ as well as an SC retrofit scenario $\left(F E_{j f 0} \neq 0\right)$.

$$
\begin{aligned}
& \sum_{k} \xi_{j f k t} F E_{j f k}^{l i m i t}=F E_{j f t} \quad \forall f, j \in \tilde{J}_{f}, t \\
& \sum_{k} \xi_{j f k t}=V_{j f t} \quad \forall f, j \in \tilde{J}_{f}, t
\end{aligned}
$$

$F_{j f t}=F_{j f t-1}+F E_{j f t} \quad \forall f, j \in \tilde{J}_{f}, t$

Eq. (10) is used to ensure an utilisation greater than or equal to a minimum value established by the decision maker and that the utilized capacity is lower than or equal to the available one. Parameter $\beta_{\text {if }}$ [adim.] defines a minimum utilisation rate of technology $j$ in site $f$ as a proportion of the total available capacity. Parameter $\theta_{i j f f}$, $[\mathrm{h} / \mathrm{kg}]$ represents the resource utilisation factor. This 
is the capacity utilisation rate, in terms of capacity units (e.g., machine-hours), of technology $j$ by task $i$ whose origin is location $f$ and destination location $f^{\prime}$.

$\beta_{j f} F_{j f t-1} \leq \sum_{f^{\prime}} \sum_{i \in I_{j}} \theta_{i j f f^{\prime}} P_{i j f f^{\prime} t} \leq F_{j f t-1} \quad \forall f, j \in \tilde{J}_{f}, t$

The capacity is expressed as equipment $j$ available time during one planning period, then $\theta_{i j f f}$ represents the time required to perform task $i$ in equipment $j$ per unit of produced material. Thus, once operation times are determined, this parameter can be readily approximated.

Eq. (11) guarantees that the amount of raw biomass $s$ purchased from site $f$ at each time period $t$ is lower than an upper bound given by physical availability $A_{\mathrm{sft}}[\mathrm{kg}]$ (e.g., seasonality, crop/plantation yield in a specific region).

$\sum_{f^{\prime}} \sum_{i \in \bar{T}_{s}} \sum_{j \in J_{i}} P_{i j f f^{\prime} t} \leq A_{s f t} \quad \forall s \in R M, f \in S u p, t$

Eq. (12) establishes that flows of energy exist only if locations $f^{\prime}$ and $f$ are interconnected. $Z_{f, f}$ is a binary variable which takes a value equal to one if $f^{\prime}$ and $f$ are interconnected, 0 otherwise; while $M$ represent a big positive number. By Eq. (13) sales of final product $s \in F P$ carried out from facility location $f^{\prime}$ to market $f \in M$ are estimated. Eq. (14) is used to express that the demand can be partially satisfied due to biomass production or supplier capacity limitations: the sales of product $s$ carried out in market $f$ during the time period $t$ could be less than or equal to the demand.

$P_{i j f^{\prime} f t} \leq M Z_{f^{\prime} f} \quad \forall s \in F P, i \in\left(T_{s} \cap T r\right), f \in M k t, t$

Sales $_{s f^{\prime} f t}=\sum_{i \in\left(T_{s} \cap T r\right)} \sum_{j \in\left(J_{i} \cap J_{f}\right)} P_{i j f^{\prime} f t} \quad \forall s \in F P, f \in M k t, f^{\prime} \notin M k t, t$

$\sum_{f^{\prime} \notin M}$ Sales $_{s f^{\prime} f t} \leq$ Dem $_{s f t} \quad \forall s \in F P, f \in M k t, t$

Here, it is important to emphasize two aspects. One is that for this sort of networks the final product is the energy delivered to the different regions $(M k T)$. Thus, for those tasks that carry out the energy generation their corresponding parameter $\alpha_{s i j}$ is determined as a function of the heating value of the input materials and the efficiency of the equipment. Finally, the energy consumed by the equipment along the SC should be discounted from the energy available to satisfy the demand once the network reaches "steady state".

\subsection{Economic model}

The expressions required to compute the operating revenue, the operation costs, the total capital investment, and NPV are next described.

The operating revenue is expressed in Eq. (15) as the product sales during period $t$.

ESales $_{t}=\sum_{s \in F P} \sum_{f \in M k t} \sum_{f^{\prime} \notin(M k t \cup \text { Sup })}$ Sales $_{\text {sf'ft }}$ Price $_{\text {sft }} \quad \forall t$

The operating costs include fixed and variable costs: Eq. (16) describes the total fixed costs of operating the SC network. FCFJ ${ }_{j f t}$ [US\$/h] is the fixed unitary capacity cost of using technology $j$ at site $f$.

$F \operatorname{Cost}_{t}=\sum_{f \notin(\text { Mkt USup })} \sum_{j \in \tilde{J}_{f}} F C F J_{j f t} F_{j f t} \quad \forall t$
In turn, as variable costs, the cost of purchases from supplier $e$, includes raw material procurement, transport and production resources, as shown in Eq. (17). The purchases of raw materials (Purch et $^{m}$ [US\$]) made to supplier $e$ are evaluated in Eq. (18). We will assume a different supplier for each component of the variable costs. This assumption can be easily relaxed to account for the specifics of the problem being dealt with. The variable $\chi_{\text {est }}[\mathrm{US} \$ / \mathrm{kg}$ ] represents the cost associated with raw material $s$ purchased to supplier $e$. Transportation and production variable costs are determined by Eqs. (19) and (20), respectively. $\rho_{\text {eff } t}^{t r}$ [US\$/kg] denotes the $e$ provider unitary transportation cost associated with material distribution from location $f$ to location $f^{\prime}$ during period $t$. $\tau_{i j f e t}^{u t 1}[\mathrm{US} \$ / \mathrm{kg}]$ represents the unitary production cost associated to perform task $i$ using technology $j$, whereas $\tau_{\text {sfet }}^{u t 2}[\mathrm{US} \$ / \mathrm{kg}]$ represents the unitary inventory costs of material $s$ storage at site $f$. The parameter $\tau_{i \text { ifet }}^{\text {ut } 1}$ entails similar assumptions to the ones considered with regard to $\alpha_{s i j}$ and $\bar{\alpha}_{s i j}$, namely, the amount of utilities and labour required by an activity are proportional to the amount of material processed.

$$
\begin{aligned}
\text { EPurch }_{e t}= & \text { Purch }_{e t}^{r m}+\text { Purch }_{e t}^{t r}+\text { Purch }_{e t}^{\text {prod }} \quad \forall e, t \\
\text { Purch }_{e t}^{r m}= & \sum_{s \in R M} \sum_{f \in F_{e}} \sum_{i \in \bar{T}_{s}} \sum_{j \in J_{i}} P_{i j f f t} \chi_{e s t} \quad \forall e \in E_{r m}, t \\
\text { Purch }_{e t}^{t r}= & \sum_{i \in T r} \sum_{j \in J_{i} \cap J_{e}} \sum_{f} \sum_{f^{\prime}} P_{i j f f ' t} \rho_{e f f ' t}^{t r} \quad \forall e \in \bar{E}_{t r}, t \\
\text { Purch }_{e t}^{\text {prod }}= & \sum_{f} \sum_{i \notin T r} \sum_{j \in\left(J_{i} \cap \hat{J}_{f}\right)} P_{i j f f t} \tau_{i j f e t}^{u t 1} \\
& +\sum_{s} \sum_{f \notin(\operatorname{Sup} \cup M k t)} S_{s f t} \tau_{s f e t}^{u t 2} \quad \forall e \in \tilde{E}_{p r o d}, t
\end{aligned}
$$

The total capital investment on fixed assets is calculated by means of Eqs. (21) and (22). These equations include the investment made to expand the technology's capacity $j$ in facility site $f$ in period $t$. The investment required to connect two different locations $f$ and $f^{\prime}$ by using a medium voltage network (Invest ${ }^{M V}$ [US\$/ $\mathrm{km}]$ ) is just accounted in the first planning period. Recall that economies of scale for technologies capacity is considered using a piecewise linear approximation in $K$ intervals. Here, Price ${ }_{j \text { lim }}^{\text {it }}$ [US\$] is the investment for a capacity expansion equal to the limit of interval $k\left(F E_{j f k}^{\text {limit }}[\mathrm{h}]\right)$.

$$
\begin{aligned}
\text { FAsset }_{t}= & \sum_{f} \sum_{j} \sum_{k} \text { Price }_{j f k}^{\text {limit }} \xi_{j f k t} \\
& +\sum_{f} \sum_{f^{\prime}} \text { Invest }^{M V} \text { distance }_{f f} Z_{f f^{\prime}} \quad \forall t=0 \\
\text { FAsset }_{t}= & \sum_{f} \sum_{j} \sum_{k} \text { Price }_{j f k}^{\text {limit }} \xi_{j f k t} \quad \forall t>0
\end{aligned}
$$

Finally, Eq. (23) calculates the profit in period $t$, as operating revenues minus fixed and variable operating costs. The NPV is calculated as in Eq. (24).

$$
\begin{aligned}
& \text { Profit }_{t}=\text { ESales }_{t}-\left(\text { FCost }_{t}+\sum_{e} \text { EPurch }_{e t}\right) \quad \forall t \\
& N P V=\sum_{t}\left(\frac{\text { Profit }_{t}-\text { FAsset }_{t}}{\left(1+i_{r}\right)^{t}}\right)
\end{aligned}
$$




\subsection{Environmental model}

The application of the life cycle assessment (LCA) methodology to the SC model requires four steps according to ISO documents (ISO14040): goal definition and scope, life cycle inventory (LCI), life cycle impact assessment (LCIA) and results interpretation. Environmental interventions are translated into metrics related to environmental impact as end-points or mid-points metrics by the usage of characterisation factors. Eq. (25) calculates $I C_{\text {aft }}$ [points] which represents the mid-point environmental impact $a$ associated with site $f$, as a consequence of carrying out activities in period $t$. In turn, $\psi_{\text {ijf ' } a}$ [points $/ \mathrm{kg}$ ] is the $a$ characterisation factor of the environmental category impact for task $i$ performed using technology $j$, receiving materials from node $f$ and delivering them at node $f^{\prime}$.

$I C_{a f t}=\sum_{j \in \tilde{J}_{f}} \sum_{i \in I_{j}} \sum_{f^{\prime}} \psi_{i j f f^{\prime} a} P_{i j f f^{\prime} t} \quad \forall a, f, t$

Analogously to $\alpha_{s i j}$ and $\bar{\alpha}_{s i j}$, the value of $\psi_{i j f f^{\prime} a}$ is fixed and constant, since all environmental impacts are considered linearly proportional to the activity performed in the node (variable $P_{i j f f t}$ [kg]) [48]. Environmental impacts associated with transportation, has as a common functional unit (FU), the amount of kg of transported material over a given distance $(\mathrm{kg} \cdot \mathrm{km})$. Consequently, the value of the mid-point environmental impact $\psi_{i j f f^{\prime} a}$ associated with transport, is calculated as in Eq. (26), where $\psi_{\text {iff' } a}^{T}$ [points $\left./(\mathrm{kg} \cdot \mathrm{km})\right]$ represents the $a$ characterisation factor of the environmental category impact for the transportation of a mass unit of material over a unit of length. Note that the impact is assigned to the origin node. The environmental impacts associated with production (Eq. (25)) or transportation (Eq. (26)), can be computed by setting the indices summation over the corresponding tasks $(i \in \operatorname{Tr}$ or $i \in N T r)$. A tortuosity factor (Tortuosity [adim.]) may be employed to correct the estimated distance between nodes.

$\psi_{i j f f^{\prime} a}=\psi_{i j a}^{T}$ distance $_{f f}$ Tortuosity $\quad \forall i \in \operatorname{Tr}, j \in J_{i}, a, f, f^{\prime}$

Eq. (27) introduces $\operatorname{Dam}_{\mathrm{gft}}$ [points], which is a weighted sum of all mid-point environmental interventions. They are combined using $g$ endpoint damage factors $\zeta_{a g}$ [adim.], normalised with Norm $F_{g}$ factors. Moreover, Eq. (28) calculates $g$ normalised endpoint damage along the SC (DamC $C_{g}^{S C}$ [points]).

$D_{a m C_{g f t}}=\sum_{a \in A_{g}} N o r m F_{g} \zeta_{a g} I C_{a f t} \quad \forall g, f, t$

$\operatorname{DamC}_{\mathrm{g}}^{\mathrm{SC}}=\sum_{f} \sum_{t} \operatorname{DamC}_{\mathrm{gft}} \quad \forall \mathrm{g}$

Eqs. (29) and (30) sum the endpoint environmental damages for each site $f$ and for the whole SC, respectively.

Impact $_{f}^{2002}=\sum_{g} \sum_{t}$ DamC $_{g f t} \quad \forall f$

Impact $_{\text {overall }}^{2002}=\sum_{f} \sum_{g} \sum_{t}$ DamC $_{\mathrm{gft}}$

For further details regarding the operational and environmental formulation the interested reader is referred to [46] and [49].

\subsection{Social model}

The proposed approach consists in a criterion that counts the number of sites that have a treatment or pre-treatment system installed. The aim is to install as many as possible to promote working places in the widest range of communities or demand sites. Therefore, the social criterion SoC should be maximised (see Eq. (31)). This criterion assigns a value of 1 to each unit installed per site $f$. $V$ is the binary variable that characterises the number of units installed per site. This is not applied for storage.

SoC $=\sum_{j} \sum_{f} \sum_{t} V_{j f t} \quad \forall j, f, t$

So C can be used as objective function along with the NPV and Impact ${ }_{\text {overall }}^{2002}$ in the MO-MILP formulation. An $\varepsilon$-constraint approach will be used to tackle the MO-MILP.

The overall optimisation problem can be posed mathematically as follows:

$\underset{\mathscr{M}, \mathscr{Y}}{\operatorname{Min}}\left\{-N P V\right.$, Impact $\left._{\text {overall }}^{2002},-\mathrm{SoC}\right\}$

subject to Eqs. (1)-(31);

$\mathscr{X} \in\{0,1\} ; \mathscr{Y} \in \mathbb{R}^{+}$

Where, $\mathscr{X}$ denotes the binary variables set, while $\mathscr{Y}$ corresponds to the continuous variable set.

\subsection{Multi-objective strategy}

The multiple criteria decision-making process aims at finding the most suitable solution for the decision-maker point of view. Decision problems usually present multiple and conflicting criteria to evaluate the available alternatives. It is then necessary to make compromises or trade-offs regarding the results of the different possible choices. Instead of giving one specific solution, the multiobjective optimisation provides the so-called PF (Pareto frontier). This frontier represents a set of solutions that are not nondominated by any other feasible solution [50]. This paper assumes that the decision-maker priorities are not known, therefore, the analysis is focused on a general perspective based on the characteristics of the PF and the most important features of the scenarios that optimise each one of the selected objective functions.

- Concerning individual objective functions optimisation, extreme scenarios are obtained and characterised by solutions derived from NPV maximisation, Impact 2002 + minimisation and SoC maximisation. As more than two objectives are considered, iso-lines are used to graphically represent the three parameters bidimensionally. The iso-lines represent a fixed value for the $\mathrm{SoC}$ range. This is possible due to its discrete nature. The range of values is determined using the SoC values obtained from the extreme scenarios.

- Once the $\mathrm{SoC}$ range is established, for each of its discrete values, a bi-objective optimisation for the NPV and Impact 2002+ is carried out. Firstly, two extreme points are obtained by the single optimisation of NPV and Impact 2002 + considering a fixed value for the $S o C$. The intermediate PF points are then determined. Those Pareto solutions are found using $\varepsilon$-constraint method, that utilises a set of single objective (NPV) optimisation cases, while the remaining objective (Impact $2002+$ ) is set as an upper limit constraint. In this specific case study, 10 intermediate points are determined. Each one of the 12 solutions is a different network configuration. Please find more details about the $\varepsilon$-constraint methodology in [51].

- One of the disadvantages of some multi-objective optimisation methodologies such as the $\varepsilon$-constraint and the weighted sum is that they may provide dominated solutions, i.e., solutions for 


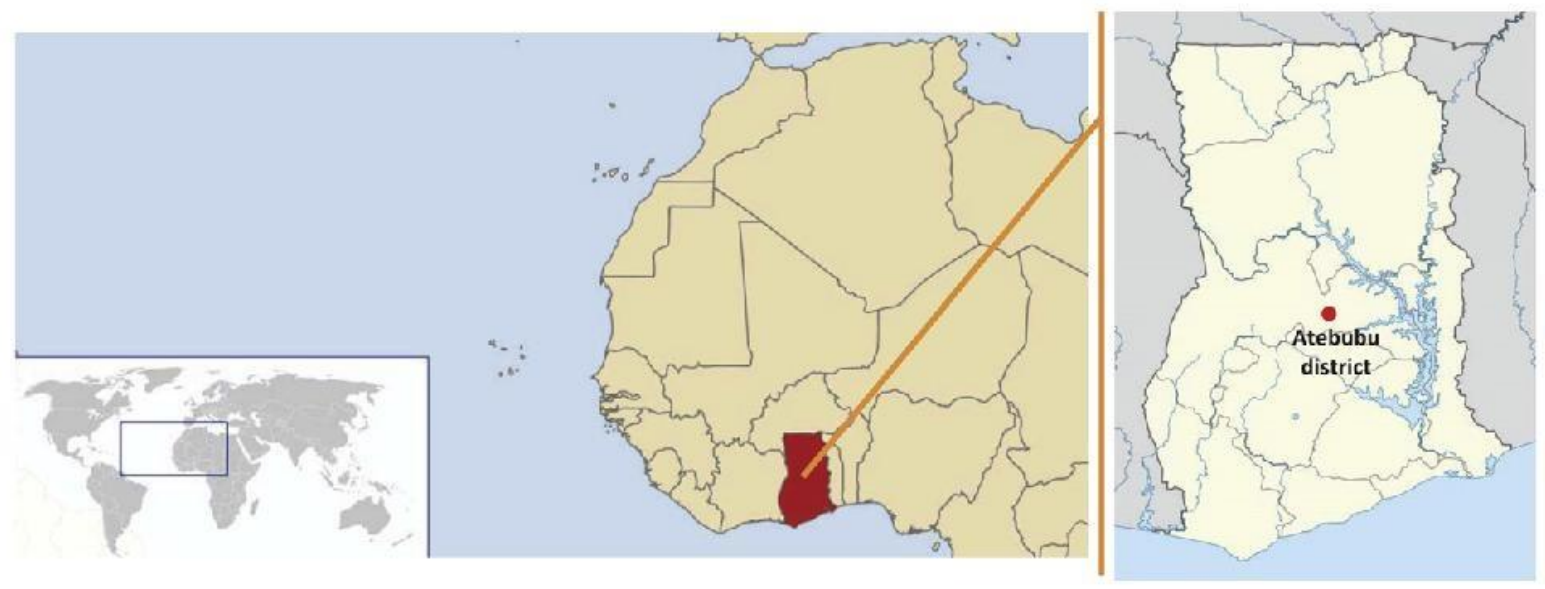

Fig. 2. Location of Atebubu district, in Ghana.

which other ones that improve an objective without worsening another one are available. A filtering step is applied to remove such solutions to construct the PF. The filter works by comparing every point with every other generated point. If a point turns out to be dominated by other point, it is eliminated [51]. The decision-maker will then select a point (network) belonging to the PF.

\section{Case study: A bio-based supply chain located in Ghana using gasification}

The generic BSC considered in the mathematical formulation (Fig. 1), is adapted to suit the intrinsic nature of the case study:

- A regional configuration deals with short distances. Owing to this, chipping and drying are the selected pre-treatments. Advanced pre-treatment methods such as fast pyrolysis, torrefaction or pelletisation are disregarded since the small biomass quantities required to supply the electricity demand does not allow to take profit from economies of scale. In addition to that, they are too complicated technologies for rural areas in developing countries. Biomass waste is pre-processed before gasification to obtain the requiered shape, LHV and MC. Storage serves as a biomass reservoir to leverage capacities from several sites and seasonality.

- The region does not have access to the grid. Customers can be therefore connected to a specific-built LV (low voltage) or a MV (medium voltage) microgrid. The LV distribution line supplies a community and the MV line, of $36 \mathrm{kV}$, connects different communities. The investment cost is contemplated.

- Each community represents one unique consumer.

This case study contemplates a specific rural area of a developing country, Ghana (Africa). Nine communities in AtebubuAmantin district, in the Brong Ahafo Region (see Fig. 2) are of concern. The biggest community is Kumfia with 2834 people, and the smallest one is Nwunwom with 122 people. See Appendix A for further details. The raw material is cassava waste. Cassava is a well extented tropical crop in the country, mainly used to provide food (in the form of fufu or gari). Agriculture is the most important economic sector, with cassava, yam and maize as basic products.

The selected communities form a region with a main characteristic: they are equipped with a MFP (multi-functional platform) that currently supplies the electricity needs; cell phone's battery charging, water refrigeration, lighting, radio, TV, computer and maize mills and cassava graters. Those communities are therefore used to pay for the electricity service. Data for the BSC characterisation are provided by local entities. The Energy Center, in Kwame NKrumah University of Science and Technology (KNUST), and the NGO Kumasi Institute of Technology, Energy and Environment (KITE). The MFP's project in Atebubu district has been executed in collaboration with KITE and the NGO Women and Children Support Organisation (WACSO). Prices for transportation and utilities valorisation, as well as specific information about the cassava crop, have been obtained during an on-field travel. The boundaries considered are from cradle-to-gate. The currency is US\$2010. The applied currency conversion is 1 Ghana cedi per US\$0.65946 [52].

\subsection{Raw material}

Cassava is also called manioc, manihoc, yuca, mandioca, aipin, catelinha, macaxeira and tapioca. The cassava waste is pilled in the farms and used for fertilisation or to feed pigs or poultry. Leaves from cassava crops are used for food (soups). The stalk is used to replant the crop. The underground cassava plant can be divided into rhizome and root. In turn, the root has three main components: pulp, starch and peels. Starch is the main product and it is used for food. The most extended uses for cassava residues is ethanol production (pulp), biogas and activated carbon production (peels) [53,54].

Cassava rhizome is the biomass waste considered in this study. The cassava is planted once a year, in April, during the rainy season ${ }^{1}$ and does not need any special care. It takes from 3 to 6 months to grow, depending on the plant type. The harvesting period is assumed to be from June to October. A $66.5 \%$ of the tubercle is cassava rhizome [55]. As the produced wastes have no current alternative use, the cost of acquisition is considered negligible. Table 1 summarises the cassava main properties. The last column sums up the total amount of cassava waste produced by the 9 communities. This value has been calculated by considering that from the total amount produced in Atebubu district, only a 20\% can be taken for electricity purposes. According to [56], 264649t of cassava has been produced during 2009 in the whole Atebubu district, representing $17667.6 \mathrm{GJ} / \mathrm{y}$.

Fig. 3 represents the production of cassava waste per community in GJ/month. The agricultural activity is supposed evenly divided among the communities according to their population. Cassava waste disposal takes place at the same generation place. See also in Fig. 3 the aggregated thermal demand estimated for the

\footnotetext{
${ }^{1}$ Conversation with cassava farmers from Seneso.
} 
Table 1

Feedstock properties.

\begin{tabular}{llllll}
\hline Biomass & $\begin{array}{l}\text { Cost } \\
(\$ / \mathrm{t})\end{array}$ & $\begin{array}{l}\mathrm{LHV}_{\mathrm{ar}} \\
(\mathrm{MJ} / \mathrm{kg})\end{array}$ & $\begin{array}{l}\mathrm{MC} \\
(\% \mathrm{wt})\end{array}$ & Seasonality & $\begin{array}{l}\text { Yearly } \\
\text { available (t) }\end{array}$ \\
\hline Cassava waste & 0 & 10.61 & 42.50 & June-October & 1666.13 \\
\hline
\end{tabular}

nine communities. These numbers are derived from the electricity demand and the gasification efficiency.

\subsection{Technologies used and electricity demand}

Inlet biomass to the gasifier must be chipped and have $20 \%$ or less of MC. It is supposed that the only possible biomass storage is carried out before chipping and gasification using on-field storage which is the cheapest and simplest option. Fig. 4 shows the layout of the different pre-treatment options applied to the biomass (BM). MC, DM, shape and LHV change along the network.

It is assumed that chipper and dryer work an average of $8 \mathrm{~h} / \mathrm{d}$. The gasifier is assumed to work $16 \mathrm{~h} / \mathrm{d}$. The project has a lifespan of 10 years [57]. Estimation of chipper and dryer available range of capacity takes into account the processed maize in an MFP during one day and the total production of cassava estimated per year. The investment and O\&M costs are taken from the literature. Economies of scale are considered. The percentages and proportions used to linearly model the activities in the mathematical formulation and to calculate the biomass states are summarised below.

- Biomass waste generation. The cassava is harvested and the rhizome is separated from the rest of the plant.

- On-site pre-treatment. Biomass is stored in biomass generation sites. Therefore, open air storage, in open air piles, takes place here.

- Drying. Passive drying is a consequence of the open air storage. According to [58], storage at the roadside is free and has negligible O\&M cost. Raw biomass with an MC higher than $20 \%$, has a DM loss per month of $3 \%$, and an MC loss per month of $2 \%$. 12 months is the maximum storage period. Active drying takes place into a rotatory drum. This unit is used to decrease the inlet MC to the required 20\%. Biomass changes its MC and its LHV according to the tonnes of water evaporated. This unit has an energy efficiency of $99 \%$. It consumes diesel as utility. The available capacities are between 0.1 and $5 \mathrm{t} / \mathrm{h}$.

- Chipping. Chipping is placed after drying. It consumes electricity from the G-ICE system. This unit has an energy efficiency of $96 \%$. The available capacities are in the range of $0.1-5 \mathrm{t} / \mathrm{h}$.

- G-ICE system. The most important parameters in the biomass gasifier, which influence the producer gas composition, are the amount of inlet air (i.e., the equivalence ratio, ER) and the MC. See the main system's parameters in Table 2; temperature of the producer gas at the gasifier outlet stream ( $\left.T_{\text {gasif }}\right)$, producer gas composition and LHV, power and heat outputs, as well as the partial (cold gas efficiency, CGE) and overall $(\eta)$ efficiencies of the system [33]. $\eta$ is used in the mathematical model to describe this activity. The gasification units range between 5 and $100 \mathrm{~kW}_{e}$.

- Transportation. Solid biomass can be displaced from its point of generation to a storage place or to a pre-treatment node by tractors, within a capacity of $10 \mathrm{t}^{2}$ Lineal distances, with a tortuosity factor of 1.8 , are considered and expressed in $\mathrm{km}$.

- LV and MV distribution grids. The LV distribution line has a 6\% losses in energy terms. The MV distribution line takes into

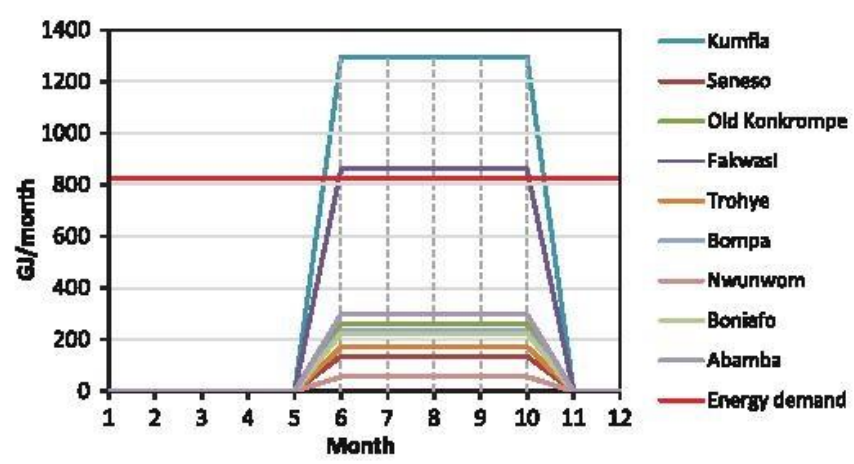

Fig. 3. Seasonal cassava waste production and thermal power demand.

account losses estimated by [59], which are proportional to the power demand. See Appendix A for further details.

The economic evaluation is based on estimations of investment and annual O\&M costs. The total capital requirement is spent at the beginning of the project. Table 3 lists the parameters needed for costs estimation of pre-treatment units, G-ICE plant and transportation. The diesel price is $\$ 1133.31 / \mathrm{t}^{3}$ The electricity price is $\$ 0.233 / \mathrm{kWh}$, as the value that the communities are willing to pay. Its calculation takes into account the consumption of diesel and batteries, and their respective prices based on data from the Seneso community.

The electricity demand has been estimated on the basis of references from previous experiences on rural electrification projects, in West Africa and South American communities. It takes into account residential, community and commercial electricity requirements. See additional details in Appendix A. The highest gross demand is $448.65 \mathrm{kWh} / \mathrm{d}$ in Kumfia community, while the lowest is $21.17 \mathrm{kWh} / \mathrm{d}$ in Nwunwom community. Such figures take into consideration the LV microgrid losses. Fig. 5 depicts the nine communities represented by their relative energy demands (in blue), in a square grid that represents their relative distance in $\mathrm{km}$. Black points mark potential locations for pre-treatment and treatment units; all the communities and four more intermediate sites are considered as potential locations.

\subsection{Environmental impact}

Impact $2002+$ metric evaluates the environmental impact in points (pts). LCI values are retrieved from LCI database [62] using [63], and they are directly converted into Impact 2002+ mid-point indicators in the so-called LCIA step. The evaluated BSC echelons are biomass production (cassava rhizome obtaining) without transportation, transportation by tractors, all pre-treatment possibilities (chipper and dryer) and generation of electricity by means of biomass gasification. The impact of this last task has been adapted from a large scale gasification plant impact, an IGCC, considering efficiency difference, in energy terms, among the two plants. For further details on LCI values, see [33].

\subsection{Model characteristics}

This case study includes 40 different biomass states (s). Set $j$ includes 6 different equipment technologies in accordance with the different pre-treatment and treatment technologies and means of transportation. The set of activities $i$ comprises 79 elements 


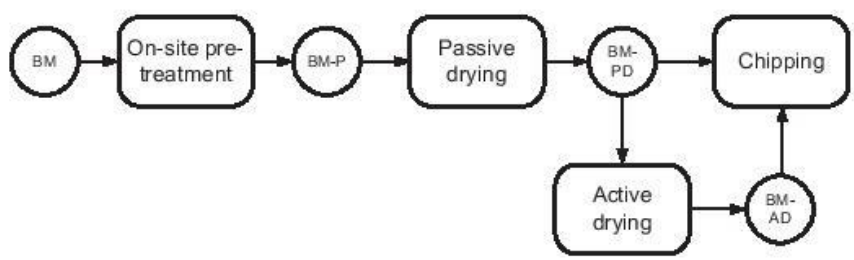

Fig. 4. Pre-treatment activities layout.

depending on the couple biomass-processing and transportation activities. Set $f$ considers sites location, being overall 31 of them; involving suppliers, pre-treatment, treatment, potential locations and markets sites. This case study considers biomass evaluated in mass basis for transportation economic accounting. The planning period $t$ represents a month. The project is evaluated along a planning horizon of 10 years. The interest rate is 15\% [64].

The mathematical model has been written in GAMS and solved using CPLEX 11.0 on a PC Intel(R) Core(TM) i7-2620M CPU $2.70 \mathrm{GHz}$ and $4.00 \mathrm{~Gb}$ of RAM. The optimisation model contains 27122 equations, 818215 continuous and 1115 discrete variables. The CPU time spent to find a single Pareto solution ranges from $32.5 \mathrm{CPU}$ s to 30857.2 CPU s. The first one correspond to the extreme scenario that minimises the environmental impact for SoC equal to 27. The highest value is for the environmental impact minimisation scenario for SoC equal to 18 . Generally, as the social factor increases, the calculation time decreases. In general, it is appreciated that the resolution of the economic criteria is less time consuming than the environmental criteria case.

\subsection{Results}

\subsubsection{Objective functions optimisation}

Extreme scenarios are obtained by individual objective functions optimisation. They are characterised by the three set of values (NPV, Impact 2002+ and SoC) derived from NPV maximisation, Impact $2002+$ minimisation and $\mathrm{SoC}$ maximisation. The optimum networks are represented by four types of matter flows that connect the different sites, disregarding the period (month of the year) when the flow appears in the resulting network. Those flows are: raw material from harvesting, stored raw material, dried matter and chipped matter, characterised by different colors in Fig. 5. Flowrates are obtained in tons/month. Note that any of the networks transports dried material. The chipped biomass is the most used alternative and the one that characterise all the networks. Since it has been assumed that cassava waste is produced into each community, proportional to the population, there is no need to employ an MV microgrid and to use the intermediate sites. Moreover, the high investment costs associated with an intermediate site prevent their use. Notice that the simplest network comes out from the environmental impact minimisation, with only chipped matter. Table 4 lists the calculated capacity of the equipments installed at each site, for each objective function.

Fig. 5(a) depicts the network that maximises the NPV. Some stored and non-stored raw matter are transported between locations. The model proposes to install a generation plant in each community but allocates the needed pre-processing facilities in only four sites: Old Konkrompe, Fakwasi, Kumfia and Abamba (see Table 4). The four sites with pre-processing units are strategically located to best handle the biomass of all the communities. The minimum chipping capacity is installed $(10 \mathrm{t} / \mathrm{h})$ in almost all the communities, which is enough to process all the needed cassava waste. Therefore, Old Konkrompe, Fakwasi, Kumfia and Abamba are centralised processing sites of cassava waste, which are four of the
Table 2

Principal output values.

\begin{tabular}{lr}
\hline Parameter & Values \\
\hline$T_{\text {gasif }}\left({ }^{\circ} \mathrm{C}\right)$ & 702.00 \\
Producer gas composition (on a mole basis) & \\
$\mathrm{CO}$ & 23.93 \\
$\mathrm{CO}_{2}$ & 10.49 \\
$\mathrm{~N}_{2}$ & 37.07 \\
$\mathrm{H}_{2}$ & 20.88 \\
$\mathrm{CH}_{4}$ & 3.58 \\
$\mathrm{H}_{2} \mathrm{O}$ & 4.03 \\
Flowrate $(\mathrm{kg} / \mathrm{h})$ & 35.33 \\
$\mathrm{LHV}(\mathrm{MJ} / \mathrm{kg})$ & 6.32 \\
$\mathrm{CGE}(\%)$ & 68.00 \\
Power $(\mathrm{kW})$ & 15.80 \\
$\eta(\%)$ & 17.00 \\
\hline
\end{tabular}

five most populated communities. Fluxes of raw material exist to supply the largest communities. Pre-treatment units installed to minimise Impact 2002 + (Table 4) have its minimum capacity at all the sites, except at the two largest, Fakwasi and Kumfia, which relies on adapted dryers and G-ICE units. Old Konkrompe, Boniafo and Abamba also have gasification plants with capacities larger than the minimum. For SoC maximisation, again, some stored and non-stored raw matter are transported between locations (see Fig. 5(c)). Fluxes of raw material exist only to supply Bompa community. The model installs each type of unit at each location, but the capacities are different if compared with the previous case, obtaining as a result a more complex network. All the pretreatment units' capacities installed correspond to the minimum value, except for Kumfia, that has a larger dryer and collects chipped biomass from other communities. Again, the gasification units are scaled to meet their respective community demand. The results show that those networks require biomass storage in order to satisfy the constant electricity demand. The storage period ranges between 5 and 8 months.

Table 5 summarises the three criteria evaluated for each optimal network. Note that the value of SoC is the same for the environmental friendly and for the most social favorable scenarios. The one that maximises the NPV when SoC is fixed to its maximum value has been identified as the maximum social criterion configuration. The economic value corresponding to the BSC configuration that maximises the NPV is $\$ 89895.95$, which is the maximum NPV that can be obtained in this case study. This value is decreased by $59 \%$ in the environmental friendly network, and by $50 \%$ in the social network. For the environmental parameter, it can be deduced that the difference among configurations mainly falls on transportation of chipped biomass. On the other hand, the Impact 2002 + value is reduced by $2.3 \%$, if the LCA is optimised instead of the NPV. Note that if the most environmental friendly option is selected, the decision maker should be willing to compromise around $60 \%$ of the optimum NPV which implies just a $2 \%$ improvement in the environmental metric. In order to decrease the environmental impact, there is a necessity of more decentralised units. This requires a significant greater investment in comparison with the NPV optimum alternative. Notwithstanding, the gain in the environmental impact only results from a reduction in transportation. The NPV optimal solution has an environmental impact of 113.46 pts, whereas the Impact 2002 + optimum scenario has 110.94 pts and the social optimum network has 111.43 pts. The environmental impact for the social BSC network is closer to the optimal environmental impact. The maximum value for the social criterion is 27, installing 3 units per site. The comparison between economic and social configurations show that: (i) in the former the capacity of the installed units is adapted to match the demand and, (ii) in the latter the units are 
Table 3

Economic parameters for pre-treatment units, G-ICE plant, transportation and utilities consumption. Data from [58,60,61], Ankur Scientific Energy Technologies Pvt.Ltd., KITE and WACSO.

\begin{tabular}{|c|c|c|c|c|c|}
\hline & Base scale & Base investment & $\mathrm{O} \& \mathrm{M}$ (\% of investment) & Utility consumption & Lifetime (y) \\
\hline Drying & $100 \mathrm{t} / \mathrm{h}$ & M\$10.5 & 3 & $0.06 \cdot t_{\mathrm{H}_{2} \mathrm{Oev}}(\mathrm{t}$ diesel $)$ & 15 \\
\hline Chipping & $80 \mathrm{t} / \mathrm{h}$ & $\mathrm{M} \$ 1.2$ & 20 & Bond law $0.15 \cdot t$ input $(\mathrm{kW})$ & 15 \\
\hline G-ICE system & $20 \mathrm{~kW}_{e}$ & $M \$ 0.05^{\mathrm{a}}$ & 4 & & 7 \\
\hline Transportation biomass & & Tractor full $\$ 0.32 / \mathrm{km} \cdot \mathrm{t}$ & Loading and offloading $\$ 1.32 / \mathrm{t}$ & & \\
\hline MV network ${ }^{\mathrm{b}}$ & & $\$ 5000 / \mathrm{km}$ & & & \\
\hline
\end{tabular}

a LV network costs are included here.

b Transformer cost is $\$ 1000$.
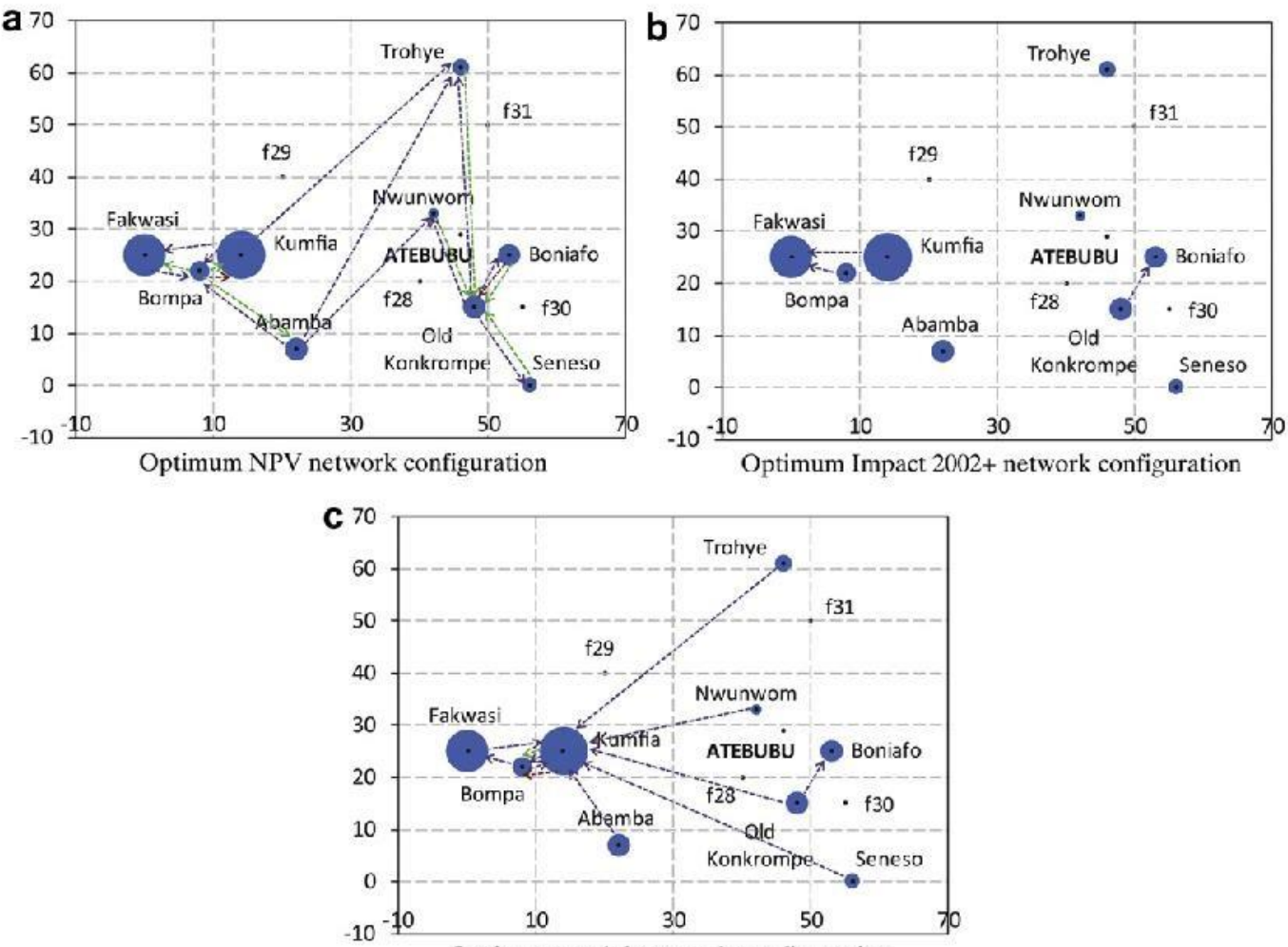

Optimum social network configuration

Fig. 5. Optimum networks configuration for the three selected criteria. Axes in km. See in brown the non-stored raw matter flow, in green, the raw matter flow, in orange the dry matter flow and in purple the chipped matter flow.

installed and then operated to meet the demand. Thus, a certain centralisation is needed in DES to ensure the sustainability if the network.

Fig. 6 depicts the investment and the annual costs breakdown for each described optimal BSC. Investment costs are \$284422, $\$ 343187$ and \$331967 for NPV, Impact 2002+ and social optimised scenarios, respectively. The utilities costs for each BSC are around $\$ 26000 / y$ due to the diesel consumption of the dryer, that processes about the same amount of biomass into each network. Note that the economic optimum scenario has the lowest investment costs, but the highest operational costs. The opposite occurs in the environmental friendly scenario. The difference results from the trade-off

Table 4

Equipment capacity for the optimum networks configurations obtained for the three selected criteria.

\begin{tabular}{|c|c|c|c|c|c|c|c|c|c|}
\hline & \multicolumn{3}{|l|}{ NPV max } & \multicolumn{3}{|l|}{ Impact min } & \multicolumn{3}{|l|}{ SoC max } \\
\hline & Dryer $(t / h)$ & Chipper $(\mathrm{t} / \mathrm{h})$ & G-ICE (MJ/h) & $\operatorname{Dryer}(\mathrm{t} / \mathrm{h})$ & Chipper $(\mathrm{t} / \mathrm{h})$ & G-ICE (MJ/h) & Dryer $(\mathrm{t} / \mathrm{h})$ & Chipper $(\mathrm{t} / \mathrm{h})$ & G-ICE (MJ/h) \\
\hline Seneso & & & 18.00 & 0.10 & 0.10 & 18.00 & 0.10 & 0.10 & 18.00 \\
\hline Old Konkrompe & 0.10 & 0.10 & 21.44 & 0.10 & 0.10 & 21.44 & 0.10 & 0.10 & 21.44 \\
\hline Fakwasi & 0.14 & 0.10 & 80.61 & 0.14 & 0.10 & 80.61 & 0.10 & 0.10 & 80.61 \\
\hline Kumfia & 0.20 & 0.11 & 102.35 & 0.19 & 0.10 & 102.35 & 0.12 & 0.10 & 102.35 \\
\hline Trohye & & & 18.00 & 0.10 & 0.10 & 18.00 & 0.10 & 0.10 & 18.00 \\
\hline Bompa & & & 18.00 & 0.10 & 0.10 & 18.00 & 0.10 & 0.10 & 18.00 \\
\hline Nwunwom & & & 18.00 & 0.10 & 0.10 & 18.00 & 0.10 & 0.10 & 18.00 \\
\hline Boniafo & & & 20.53 & 0.10 & 0.10 & 20.53 & 0.10 & 0.10 & 20.53 \\
\hline Abamba & 0.10 & 0.10 & 22.04 & 0.10 & 0.10 & 22.04 & 0.10 & 0.10 & 22.04 \\
\hline
\end{tabular}


Table 5

Economic, environmental and social aspects for the individual objective functions optimised networks.

\begin{tabular}{lr}
\hline NPV optimization (\$) & 89895.95 \\
Impact 2002+ (pts/y) & 113.46 \\
Social criterion & 17.00 \\
\hline NPV (\$) & 36867.21 \\
Impact 2002 + optimisation (pts/y) & 110.94 \\
Social criterion & 27.00 \\
\hline NPV (\$) & 45155.60 \\
Impact 2002+ (pts/y) & 111.43 \\
Social optimisation & 27.00 \\
\hline
\end{tabular}

between transportation and decentralisation. The social optimum scenario is an intermediate network.

Analogous observations can be retrieved from Fig. 7(a), where the environmental impact is depicted per SC echelon. The contribution that changes the most among the optimised networks is that of pre-processed biomass transportation. Biomass preprocessing and electricity generation constitute the major share among the intervention contributions; therefore the increase of the efficiency of these processes is crucial. Fig. 7(b) represents the environmental impact share per damage category, i.e. human health, ecosystem quality, climate change and resources. Those are in the same range for each optimum scenario. The highest impact comes from climate change, being a $80 \%$ of the whole impact.

\subsubsection{Pareto front}

The trade-off among the three selected parameters is studied in this section. SoC ranges between 17 and 27, and using the $\varepsilon$-constraint 132 networks are found. After filtering, 104 networks result as non-dominated options. Fig. 8 representats the Pareto set of solutions, NPV vs. Impact $2002+$, for each social iso-line.

It is observed that as the $\mathrm{SoC}$ increases, the environmental impact decreases at the expense of compromising the NPV. The curves for SoC equal to 17 and 18 are far from the behaviour of the other level curves. Those are the better options with regard to only the economic criterion. In the considered SoC range, the NPV varies in an interval of M\$53, while the environmental impact oscillates 1.8 pts. They represent a decrease of $59 \%$ and an increase of $2 \%$ in comparison with the single optimisation values.

\subsubsection{Sensitivity analyses}

Several sensitivity analyses have been performed to show how optimum scenarios can vary if some key parameters are changed. The effect of the electricity price $(\$ 0.233 / \mathrm{kWh})$ on the optimal NPV
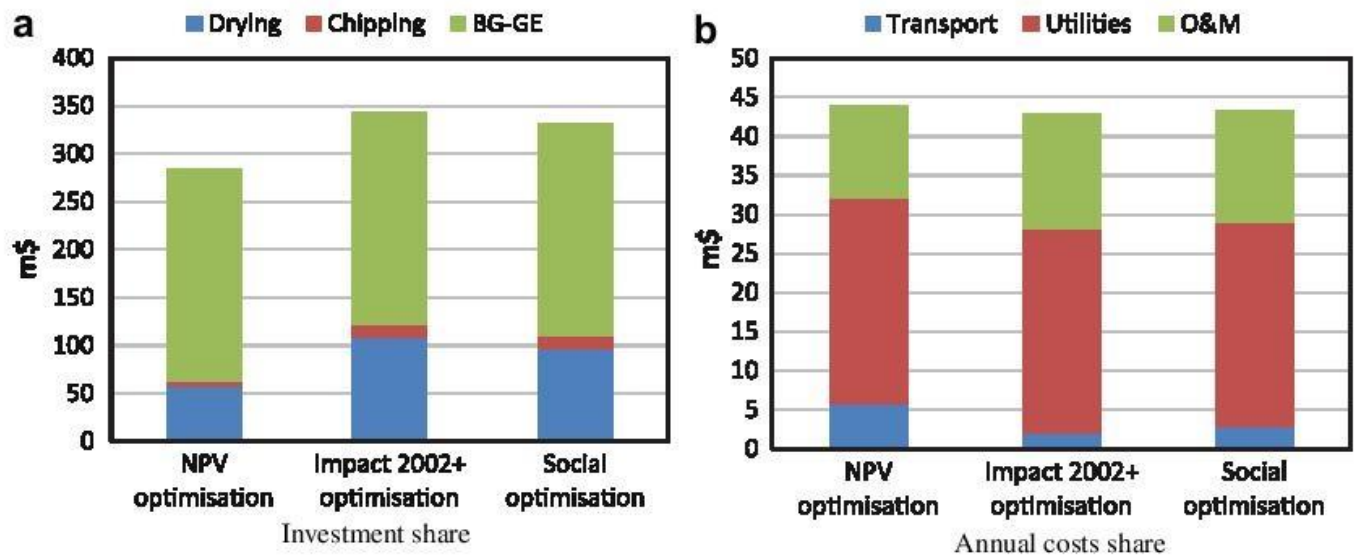

Fig. 6. Breakdown of costs for NPV, impact $2002+$ and social optimised networks.
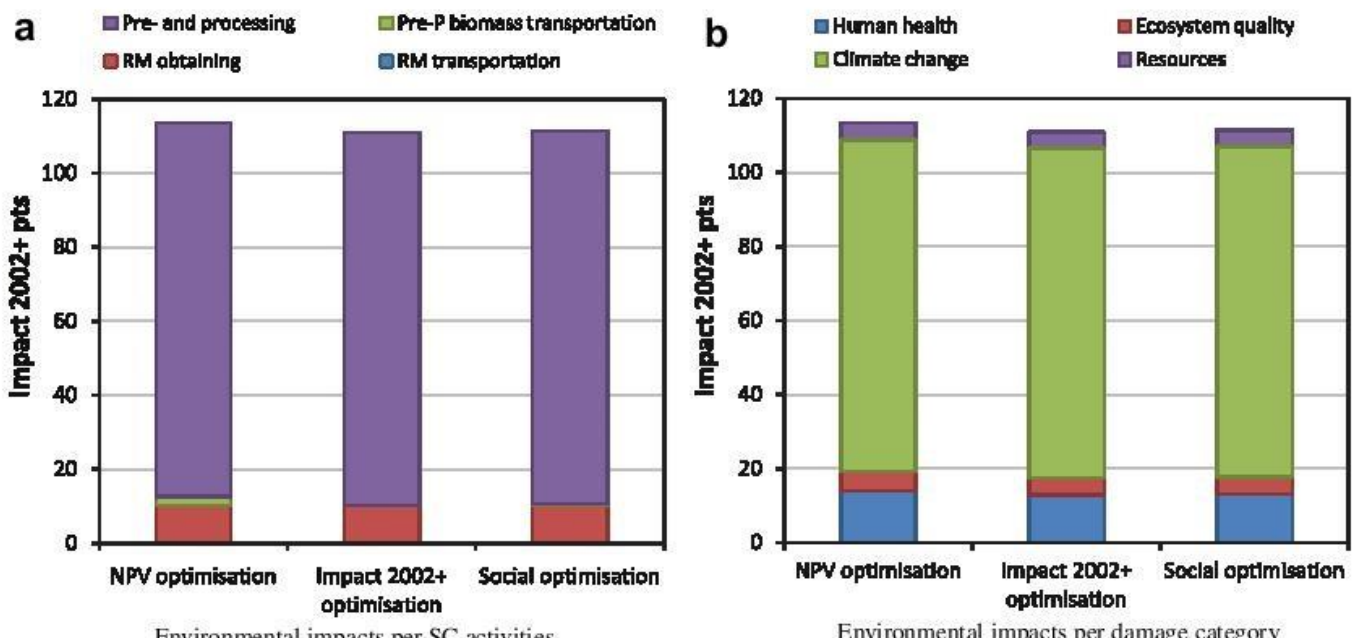

Environmental impacts per SC activities

Environmental impacts per damage category

Fig. 7. Environmental impacts arising from single optimisation results, in impact $2002+$ pts/y. 


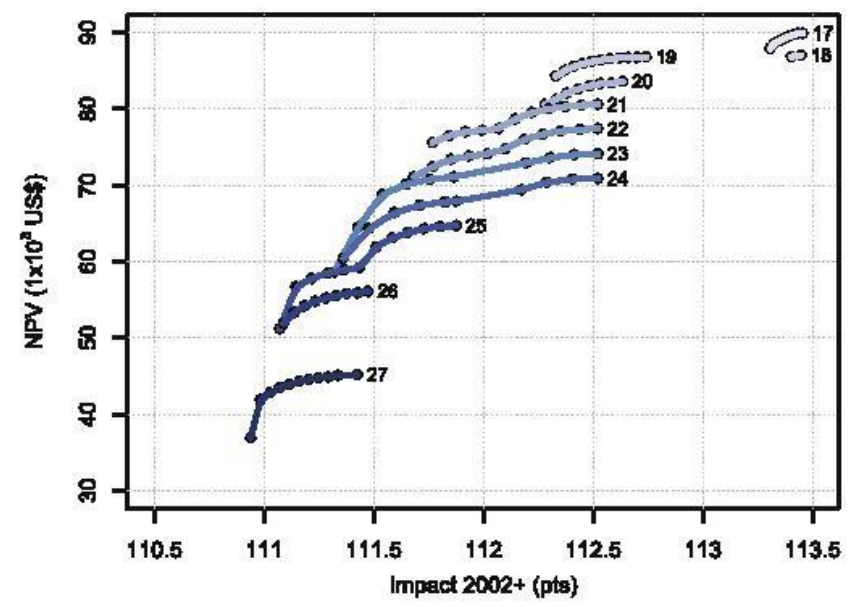

Fig. 8. Pareto set of solutions.

network considering the maximisation of the NPV, is analysed. If the electricity price is decreased, then the viability of the network breaks down, i.e. the NPV starts to be below zero. Prices lower than around $\$ 0.2 / \mathrm{kWh}$ would require a subsidy policy. Fig. 9 shows the behaviour of the internal rate of return (IRR) when changing the electricity price for economic and environmental optimum scenarios. One can see that for the same price, the economic optimum scenario improves about 5\% the IRR. For a IRR equal to zero, the maximum NPV configuration allows a electricity price value of $\$ 0.15 / \mathrm{kWh}$; whereas, the most environmental configuration allows a price value of $\$ 0.16 / \mathrm{kWh}$.

\subsubsection{Global remarks}

The needed amount of biomass to satisfy the electricity demand is $1526 \mathrm{t} / \mathrm{y}$. An $8.4 \%$ of the total available cassava rhizome is not used and can be employed for other purposes. The most important differences among the three selected criteria concern transportation and investment. Due to the cassava waste disposition, which is present in all the communities, no MV microgrid is installed. Therefore, the G-ICE plants capacity installed in all the communities, for all the Pareto solutions, are the same. The smallest communities whose demands are far from the biggest ones, such as Seneso or Nwunwom, are the communities that show more variability along the different scenarios. The largest variability comes from the chipper and dryer installations: those are the units used to adjust the social factor during the search of optimum scenarios.

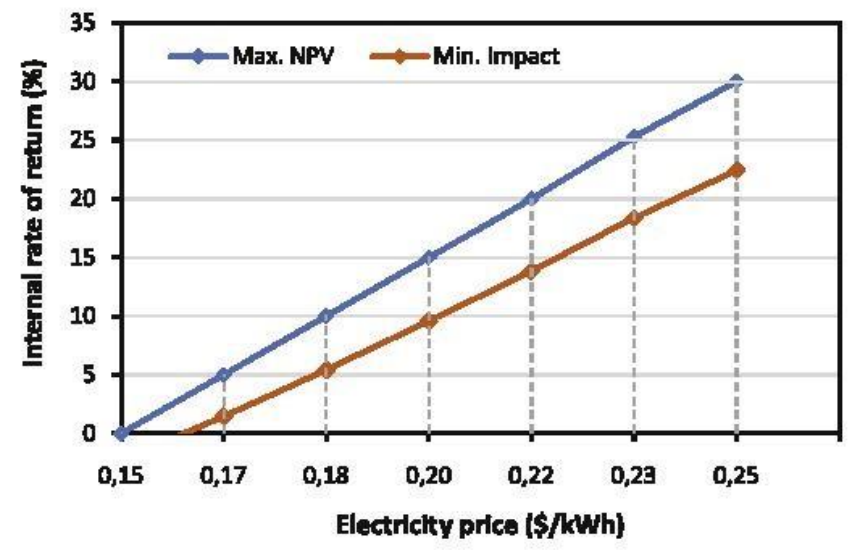

Fig. 9. IRR vs, electricity price for the economic and environmental optimum networks.
Notice that even though there is enough biomass to be selfsufficient, biomass from other communities is processed to supply the demand of small communities. By doing so, the investments in pre-treatment technologies are reduced. Such a reduction has a major contribution than the savings in transportation that would be gained if the biomass were pre-treated locally for these small communities. It is also relevant to notice that transportation of raw biomass is carried out from some small communities to other ones with installed pre-treatment capacity in order to face seasonality. At this point, the decision-maker is able to select one of the configurations represented in the $\mathrm{PF}$, according to his/her criteria.

\section{Conclusions}

This paper has demonstrated the capability and adequacy of a multi-objective mathematical programming approach for the decision-making associated with a DES network design. The mathematical model comprises three performance metrics with economic, environmental and social concerns. There does not exist a unique modelling and global approach to tackle such problems: the strategies must be adapted depending on the raw material, disposable pre-treatment units and final energy purposes. Distributed approaches should rely on a certain level of centralisation to be feasible along the planning horizon and favour the economic and social developments of regional areas. The capabilities of the proposed model have been exemplified with a case study placed in Ghana. This case study showed some centralisation of pre-treatment equipment to take economic advantages that may help to the project feasibility. The multi-objective optimisation resulted in a PF that provides crucial information for the design problem. It showed the main trends of the optimal solutions, revealing trade-offs among the economic criterion, environmental and social criteria. Once the model is built, it is possible to perform sensitivity analyses to provide information about sensible parameters and their influence in the network design. In this paper, the electricity price is analised, being eventually useful to establish price and subsidies policies that can help to motivate such projects. All the compiled information is an important input for the decisionmaking process and support the selection of the most appropriate supply chain configuration.

The energy block is the most versatile part of the model in DES configuration: this part can be easily adapted to other microgeneration sources, such as wind, hydro or solar, or even to investigate the use of more than one renewable source in hybrid systems. Part of our research agenda includes the evaluation of cogeneration and tri-generation to enhance the supply chain efficiency. The present approach can be enhanced to consider other advanced pre-treatment methods, such as pelletisation, torrefaction or pyrolysis. The mathematical model presented in this work deals with the combination of feeds and determines the optimum proportions of each input for the energy generation activity. Further work is devoted to the extension of this flexibility to other activities included in the biomass supply chain, such as storage and pre-treatment. Decomposition strategies to reduce the computational cost of solving this type of problems is also devised as future work.

\section{Acknowledgments}

We are grateful for the data provided by Mr. I. Edjekumhene and Mr. C. Nartey from KITE (Ghana), Dr. A. Addo from KNUST (Ghana) and Mr. Jacob Salifu from WACSO (Ghana). We acknowledge the financial support received from the Generalitat de Catalunya with the ESF (FI grants), the project EHMAN (DPI2009-09386) financed by the MEC and the EU FEDER fund, the CCD (UPC) grant and the 
project VALTEC08-2-0020 financed by ACC1Ó (Generalitat de Catalunya) in the framework of the Catalonia's FEDER Operational Programme.

\section{Notation}

\begin{tabular}{|c|c|}
\hline & pts and subindices \\
\hline ar & as received basis \\
\hline$e$ & electric \\
\hline th & thermal \\
\hline$e v$ & evaporated \\
\hline
\end{tabular}

Acronyms

BD bulk density

BM biomass

BSC bio-based supply chain

CGE cold gas efficiency

$\mathrm{COE}$ cost of the energy

d day

DES distributed energy systems

DM dry matter

ER equivalence ratio

G gasification

ICE internal combustion engine

IRR internal rate of return

LCA life cycle assessment

LCI life cycle inventory

LCIA life cycle impact assessment

LHV lower heating value

LP linear programming

LV low voltage

MC moisture content

MFP multi-functional platform

MO-MILPMulti-objective mixed integer linear program

MV medium voltage

NPV net present value

O\&M operation and maintenance

$\mathrm{PF} \quad$ Pareto front

SC supply chain

SCM supply chain management

STN state task network

y year

Indices

a mid-point environmental impact categories

e suppliers

$f, f^{\prime} \quad$ facility locations

$g \quad$ end point environmental impact categories

$i \quad$ tasks

$j \quad$ equipment technology

$k \quad$ intervals for piecewise linear approximation of economies of scale

$s \quad$ materials (states)

$t, t^{\prime} \quad$ planning periods

Sets

$A_{g}$

Erm

$\hat{E}_{\text {prod }}$

$\bar{E}_{t r}$

FP

$\bar{I}$ set of mid-point environmental interventions that are combined into endpoint damage factors $g$ set of suppliers $e$ that provide raw materials set of suppliers $e$ that provide production services set of suppliers $e$ that provide transportation services set of materials $s$ that are final products set of tasks $i$ with variable input set of tasks $i$ that can be performed in technology $j$
$\bar{J}_{e} \quad$ technology $j$ that is available at supplier $e$

$\tilde{J}_{f} \quad$ technology $j$ that can be installed at location $f$

$J_{i} \quad$ technologies that can perform task $i$

$J_{\text {Stor }}$ technologies to perform storage activities

Mkt set of market locations

$N T r \quad$ set of production, or non-transport, tasks

$R M \quad$ set of materials $s$ that are raw materials

$S_{\text {stor }} \quad$ set of materials/biomass that if stored change their properties

Sup set of supplier locations

$T_{S} \quad$ set of tasks producing material $s$

$\bar{T}_{s} \quad$ set of tasks consuming material $s$

$\operatorname{Tr} \quad$ set of distribution tasks

Parameters

$A_{\mathrm{sft}}[\mathrm{kg}]$ maximum availability of raw material $s$ in period $t$ in location $f$

$D_{\text {em }}$ sft $[\mathrm{MJ}]$ demand of product $s$ at market $f$ in period $t$

distance $_{f f^{\prime}}[\mathrm{km}]$ distance from location $f$ to location $f^{\prime}$

$F C F]_{j f t}[\$ / h]$ fixed cost per unit of technology $j$ capacity at location $f$ in period $t$

$F E_{j f k}^{\text {limit }}$ [h]increment of capacity equal to the upper limit of interval $k$ for technology $j$ in facility $f$

$i_{r}$ [adim.] discount rate

Invest $^{M V}[\$ / \mathrm{km}]$ investment required for medium voltage

$M$ [adim.] a big number connectivity per length unit

Norm $F_{g}$ [adim.] normalising factor of damage category $g$

Price $\left._{s f t}[\$ / M]\right]$ price of product $s$ at market $f$ in period $t$

Price ${ }_{i f k}^{l i m i t}$ [\$/MJ] investment required for an increment of capacity equal to the upper limit of interval $k$ for technology $j$ in facility $f$

Tortuosity [adim.] tortuosity factor

Water $_{s}$ [adim.] Moisture for material $s$

Water $r_{i j}^{\max }$ [adim.] Maximum moisture for task $i$ performed in equipment $j$

Greek symbols

$\alpha_{\text {sij }}$ [adim.] mass fraction of task $i$ for production of material $s$ in equipment $j$

$\bar{\alpha}_{s i j}$ [adim.] mass fraction of task $i$ for consumption of material $s$ in equipment $j$

$\beta_{j f}$ [adim.] minimum utilisation rate of technology $j$ capacity that is allowed at location $f$

$\zeta_{\text {ag }}$ [adim.] g endpoint damage characterisation factor for environmental intervention $a$

$\theta_{i j f f^{\prime}}[\mathrm{h} / \mathrm{kg}]$ capacity utilization rate of technology $j$ by task $i$ whose origin is location $f$ and destination location $f^{\prime}$

$\rho_{e f f^{\prime} t}^{t r}[\$ / \mathrm{kg}]$ unitary transportation costs from location $f$ to location $f^{\prime}$ during period $t$

$\tau_{i j f e t}^{u t 1}[\$ / \mathrm{kg}]$ unitary cost associated with task $i$ performed in equipment $j$ from location $f$ and payable to external supplier $e$ during period $t$

$\tau_{s f e t}^{u t 2}[\$ / \mathrm{kg}]$ unitary cost associated with handling the inventory of material $s$ in location $f$ and payable to external supplier $e$ during period $t$

$\chi_{\text {est }}[\$ / \mathrm{kg}]$ unitary cost of raw material $s$ offered by external supplier $e$ in period $t$

$\psi_{\text {iiff } a}[$ points $/ \mathrm{kg}$ ] $a$ environmental category impact CF for task $i$ performed using technology $j$ receiving materials from node $f$ and delivering it at node $f^{\prime}$

$\psi_{i j a}^{T}$ [points $\left./(\mathrm{kg} \cdot \mathrm{km})\right]$ a environmental category impact CF for the transportation of a mass unit of material over a length unit 
Binary variables

$V_{\text {jft }} \quad 1$ if technology $j$ is installed at location $f$ in period $t$, 0 otherwise

$Z_{f f^{\prime}} \quad 1$ if facilities $f$ and $f^{\prime}$ are interconnected by a medium voltage line, 0 otherwise

SOS2 variables

$\xi_{j f k t} \quad$ variable to model the economies of scale for technology $j$ in facility $f$ at period $t$ as a piecewise linear function

Continuous variables

$D_{a m} C_{g f t}$ [point] normalised endpoint damage $g$ for location $f$ in period $t$

$\operatorname{DamC}_{g}^{S C}$ [point] normalised endpoint damage $g$ along the whole SC

EPurch $_{\text {et }}$ [\$] economic value of purchases executed in period $t$ to supplier $e$

ESales $_{t}$ [\$] economic value of sales executed in period $t$

FAsset $t_{t}[\$]$ investment on fixed assets in period $t$

FCost $_{t}[\$]$ fixed cost in period $t$

$F_{i f t}[\mathrm{~h}]$ total capacity of technology $j$ during period $t$ at location $f$

$F E_{j f t}[\mathrm{~h}]$ capacity increment of technology $j$ at location $f$ during period $t$

$H V_{s}[\mathrm{MJ} / \mathrm{kg}]$ lower heating value for material $s$

$I C_{\text {aft }}$ [point] mid-point $a$ environmental impact associated to site $f$ which rises from activities in period $t$

Impact ${ }_{f}^{2002}$ [point] total environmental impact for site $f$

Impact 2002 overall [point] total environmental impact for the whole SC

NPV [\$] economic metric, net present value

$P_{i j f f^{\prime} t}[\mathrm{~kg}]$ specific activity of task $i$, by using technology $j$ during period $t$, whose origin is location $f$ and destination is location $f^{\prime}$

Profit $t_{t}$ \$ ] profit achieved in period $t$

$P v_{\text {sifft }}[\mathrm{kg}]$ input/output material of material $s$ for activity of task $i$ with variable input/otput, by using technology $j$ during period $t$ in location $f$ (This must be a production activity)

Profit $t$ [\$] profit achieved in period $t$

Purch $_{e t}^{p r}[\$]$ amount of money payable to supplier $e$ in period $t$ associated with production activities

Purch $_{e t}^{r m}[\$]$ amount of money payable to supplier $e$ in period $t$ associated with consumption of raw materials

Purch $_{e t}^{t r}[\$]$ amount of money payable to supplier $e$ in period $t$ associated with consumption of transport services

Sales $_{\text {sff't } t}[\$]$ amount of product $s$ sold from location $f$ in market $f^{\prime}$ in period $t$

$S_{\mathrm{sft}}[\mathrm{kg}]$ amount of stock of material $s$ at location $f$ in period $t$

SoC [unit] surrogate social metric

\section{Appendix A. Data for the case study}

Three main types of electricity demand are considered. They follow the typical regulated tariffs structure, which is the common reference in demand characterisation for stakeholders involved in the rural electrification sector.

- Residential. It covers typical household uses of electricity, such as lighting, communications and very small appliances. In rural communities without access to electricity, the majority of households (up to $70 \%$ of a community) have a very low electricity demand, in the range of 8 to $20 \mathrm{kWh}$ per month (equivalent to 250 to $700 \mathrm{Wh} / \mathrm{d}$ ), even with access to a $24 \mathrm{~h}$ service scheme.

- Community. It refers to the use of electricity in community or public premises, i.e. schools, health centres, public lighting and water pumping stations.
- Productive \& Commercial. It refers to income-generating uses of electricity, i.e. motors, large fridges or freezers, agroprocessing or sawmill equipment.

To estimate the electricity demand in Atebubu district, we have considered a reference community. It is a small rural community without previous access to electricity with 10 potential users and with 7 households. For further details on values please see [65].

Using the reference demand, the net demand of each community from our case study has been estimated as a proportion to the number of households. The current approach assumes that users will be supplied with a distribution microgrid in each community; hence, the intra-community LV distribution losses have to be estimated to approach the gross demand, that is, the electricity that needs to be supplied to each community. Based on a related International Electrotechnical Comission (IEC) standard [66], the maximum losses in an LV monophasic distribution microgrid would be kept at $5 \%$, plus a $1 \%$ of self-consumption due to the installation of meters. The resulting gross demand in each community is shown in Table A.8

Table A.8

Estimation of the net and gross electricity demands in each community, taking into account LV and MV microgrids.

\begin{tabular}{llrrrr}
\hline Community & $\begin{array}{l}\text { Number of } \\
\text { households } \\
(2010)\end{array}$ & $\begin{array}{l}\text { Population } \\
(2010)\end{array}$ & $\begin{array}{l}\text { Net } \\
\text { demand } \\
(\mathrm{kWh} / \mathrm{d})\end{array}$ & $\begin{array}{l}\text { Gross } \\
\text { demand LV } \\
\text { microgrid } \\
(\mathrm{kWh} / \mathrm{d})\end{array}$ & $\begin{array}{l}\text { Gross } \\
\text { demand MV } \\
\text { microgrid } \\
(\mathrm{kWh} / \mathrm{d})\end{array}$ \\
\hline Seneso & 46 & 296 & 42.43 & 45.00 & 61.63 \\
Old Konkrompe & 95 & 566 & 88.60 & 93.96 & 119.48 \\
Fakwasi & 359 & 1881 & 333.20 & 353.35 & 393.67 \\
Kumfia & 456 & 2834 & 423.05 & 448.64 & 501.92 \\
Trohye & 63 & 376 & 58.65 & 62.20 & 78.84 \\
Bompa & 75 & 512 & 69.88 & 74.11 & 114.43 \\
Nwunwom & 22 & 122 & 19.97 & 21.17 & 31.57 \\
Boniafo & 91 & 489 & 84.86 & 89.99 & 115.51 \\
Abamba & 98 & 653 & 91.10 & 96.61 & 122.13 \\
\hline
\end{tabular}

The model alsoconsiders the interconnection of two or several of these communities so that a centralised generation plant, coupled to an MV distribution grid, could supply more than one community. To assess this alternative, the inter-community distribution losses need to be estimated and aggregated to the gross demand in each community. Losses have been assigned to the use of step-down transformers, for load and non-load losses, assuming the use of oil transformers and an average load profile proportional to the reference shown in Fig. A.10. Reference losses are taken from [59]. Table A.8 reports the gross demand of each community if supplied by an MV microgrid.

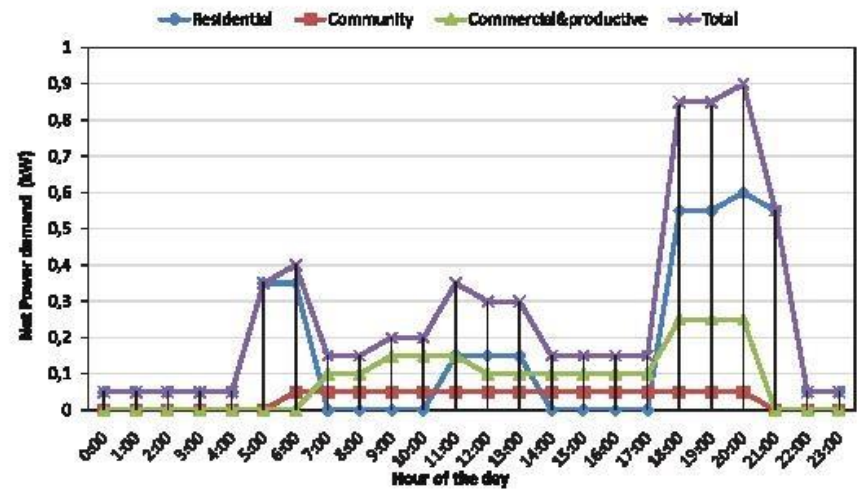

Fig. A.10. Estimated power load profile for a reference operation day in a 10 user community, considering the three types of demand and the resulting aggregated demand. The peak power demand remains below $1 \mathrm{~kW}$. 


\section{References}

[1] Sims R. Bioenergy options for a cleaner environment in developed and developing countries. 1st ed, Oxford, UK: Elsevier; 2004.

[2] Faaij A. Bio-energy in Europe: changing technology choices. Energy Policy $2006 ; 34: 322-42$.

[3] Uslu A, Faaij A, Bergman P. Pre-treatment technologies, and their effect on international bioenergy supply chain logistics. Techno-economic evaluation of torrefaction, fast pyrolysis and pelletisation. Energy 2008;33:1206-23.

[4] US Department of Energy, Energy efficiency and renewable energy: biomass program (website), Tech, rep., http://www1,eere.energy.gov/biomass/index. html, Accessed April, 2011

[5] Rosillo-Calle F, De Groot P, Hemstock SL, Woods J. The biomass assessment handbook. Bioenergy for a sustainable environment. London, UK: Earthscan; 2007.

[6] Caputo A, Palumbo M, Pelagagge P, Scacchia F. Economics of biomass energy utilization in combustion and gasification plants: effects of logistics variables. Biomass and Bioenergy 2005;28:35-51.

[7] Panichelli L, Gnansounou E. GIS-based approach for defining bioenergy facilities location: a case study in Northen Spain based on marginal delivery costs and resources competition between facilities. Biomass and Bioenergy 2008; $32: 289-300$.

[8] Ravindranath NH, Somashekar HI, Dasappa S, Reddy CNJ. Sustainable biomass power for rural India: case study of biomass gasifier for village electrification. Current Science 2004;87(7):932-41.

[9] Silva D, Nakata T. Multi-objective assessment of rural electrification in remote areas with poverty considerations. Energy Policy 2009;37:3096-108.

[10] Fleskens L, de Graaff J. Conserving natural resources in olive orchards on sloping land: alternative goal programming approaches towards effective design of cross-compliance and agri-environmental measures. Agricultura Systems 2010;103:521-34.

[11] Nidumolu U, van Keulen $\mathrm{H}$, Lubbers M, Mapfumo A. Combining interactive multiple goal linear programming with an inter-stakeholder communication matrix to generate land use options. Environmental Modelling \& Software 2007;22:73-83.

[12] Hunkeler D. Societal LCA and case study. The International Journal of Life Cycle Assessment 2006;11(6):371-82.

[13] Dreyer L, Hauschild M, Schierbeck J. A framework for social life cycle impact assessment. The International Journal of Life Cycle Assessment 2006;11(2): 88-97.

[14] Bojarski A., Life cycle thinking and general modelling contribution to chemical process sustainable design and operation, Ph.D. thesis, UPC, Barcelona, Spain, Full version in: http://tdx.cat/handle/10803/6486 (2010).

[15] Strachan N, Dowlatabadi H. Distributed generation and distribution utilities. Energy Policy 2002;30:649-61.

[16] Gold S, Seuring S. Supply chain and logistics issues of bio-energy production Journal of Cleaner Production 2011;19:32-42.

[17] Bouffard F, Kirschen D. Centralised and distributed electricity systems. Energy Policy 2008;36:4504-8.

[18] Mitra I, Degner T, Braun M. Distributed generation and microgrids for smal island electrification in developing countries: a review. Solar Energy Society of India 2008;18(1):6-20.

[19] Bayod A, Mur J, Bernal J, Domínguez J. Definitions for distributed generation: a revision. In: International Conference on renewable Energies and power quality. Spain: Zaragoza; 2005.

[20] Silva D, Nakata T. Optimization of decentralized energy systems using biomass resources for rural electrification in developing countries. Energy Policy 2008;37:3096-108.

[21] Kanase-Patil A, Saini R, Sharma M. Integrated renewable energy systems for off grid rural electrification of remote area. Renewable Energy 2010;35 $1342-9$.

[22] Hiremath R, Kumar B, Deepak P, Balachandra P, Ravindranath R, Raghunandan B. Decentralized energy planning through a case study of a typical village in India. Journal of Renewable and Sustainable Energy 2009;1. pp. 043103-1-043103-24.

[23] Cherni J, Dyner I, Henao F, Jaramillo P, Smith R, Font R. Energy supply for sustainable rural livelihoods. A multi-criteria decision-support system. Energy Policy 2007;35:1493-504.

[24] Brent A, Kruger W. Systems analyses and the sustainable transfer of renewable energy technologies: a focus on remote areas of Africa. Renewable Energy 2009; $34: 1774-81$

[25] Ferrer-Martí L, Pastor R, Capó G. Un modelo de ubicación de microaerogeneradores para el diseño de proyectos de electrificación rural con energía eólica. XIII Congreso de Ingeniería de Organización (CIO 2009); 2009.

[26] Palander T. Modelling renewable supply chain for electricity generation with forest, fossil, and wood waste fuels. Energy 2011;36:5984-93.

[27] Süle Z, Bertók B, Friedler F, Fan L. Optimal design of supply chains by P-graph framework under uncertainties. Chemical Engineering Transactions 2011;25: 453-8.

[28] Cucek L, Lam H, Klemes J, Varbanov P, Kravanja Z. Synthesis of regional networks for the supply of energy and bioproducts. Clean Technologies and Environmental Policy 2010;12:635-45.

[29] Lam H, Varbanov P, Klemes J. Regional renewable energy and resource planning. Applied Energy 2011;88:545-50.
[30] Fischer B, Pigneri A. Potential for electrification from biomass gasification in Vanuatu. Energy 2011;36:1640-51.

[31] Silva D, Nakata T. Design of decentralized energy systems for rural electrification in developing countries considering regional disparity. Applied Energy 2012;91:130-45.

[32] Siemons R. Identifying a role for biomass gasification in rural electrification in developing countries: the economic perspective. Biomass and Bioenergy 2001:20:271-85.

[33] Pérez-Fortes $M$. Conceptual design of alternative energy systems from biomass, Ph.D. thesis, UPC, Barcelona, Spain, Full version in: http://tdx.cat/ handle/10803/37913 (2011).

[34] Kirkels A, Verbong G. Biomass gasification: Still promising? A 30-year global overview. Renewable and Sustainable Energy Reviews 2011;15:471-81.

[35] Graves S, Tomlin B. Process flexibility in supply chains. Management Science 2003:49:907-19.

[36] Van Belle J, Temmerman M, Schenkel Y. Three level procurement of forest residues for power plant. Biomass and Bioenergy 2003;24:401-9.

[37] Magalhaes A, Petrovic D, Rodriguez A, Putra Z, Thielemans G. Technoeconomic assessment of biomass pre-conversion processes as a part of biomass-to-liquids line-up. Biofuels, Bioproducts and Biorefining 2009;3: $584-600$.

[38] Wu H, Yu Y, Yip K. Bioslurry as a fuel 1. Viability of a bioslurry-based bioenergy supply chain for mallee biomass in Western Australia. Energy and Fuels 2010;24:5652-9.

[39] Rentizelas A, Tolis A, Tatsiopoulos I. Logistics issues of biomass: the storage problem and the multi-biomass supply chain. Renewable and Sustainable Energy Reviews 2009;13:887-94.

[40] Forsberg G. Biomass energy transport: analysis of bioenergy transport chains using life cycle inventory method. Biomass and Bioenergy 2000;19:17-30.

[41] Yu Y, Bartle J, Li C, Wu H. Mallee biomass as a key bioenergy source in Western Australia: Importance of biomass supply chain. Energy and Fuels 2009;23: 3290-9.

[42] Pootakham T, Kumar A. Bio-oil transport by pipeline: a techno-economic assessment. Bioresource Technology 2010;101:7137-43.

[43] Pootakham T, Kumar A. A comparison of pipeline versus truck transport of bio-oil. Bioresource Technology 2010;101:414-21

[44] Ren H, Zhou W, Nakagami K, Gao W. Integrated design and evaluation of biomass energy system taking into consideration demand side characteristics. Energy 2010;35:2210-22.

[45] Ghosh D, Sagar A, Kishore V. Scaling up biomass gasifier use: an applicationspecific approach. Energy Policy 2006;34:1566-82

[46] Laínez-Aguirre J, Kopanos G, Espuña A, Puigjaner L. Flexible design-planning of supply chain networks. AIChE Journal 2009;55:1736-53.

[47] Kondili E, Pantelides C, Sargent R. A general algorithm for short term scheduling of batch operations. Computers \& Chemical Engineering 1993;17: 211-27.

[48] Heijungs R, Suh S. The computational structure of life cycle assessment Dordrecht The Netherlands: Kluwer Academic Publishers; 2002.

[49] Bojarski A, Laínez-Aguirre J, Espuña A, Puigjaner L Incorporating environmental impacts and regulations in a holistic supply chains modeling: an LCA approach. Computers \& Chemical Engineering 2009;33(10):1747-59.

[50] Turban E, Aronson J, Liang T. Decision support systems and intelligent systems. 7th ed. New Jersey, USA: Pearson Prentice Hall; 2005.

[51] Messac A, Ismail-Yahaya A, Mattson C. The normalized normal constraint method for generating the Pareto frontier. Structural and Multidisciplinary Optimization 2003;25:86-98.

[52] OANDA - Forex trading and exchange rates services, website: http://www. oanda.com, Accessed April, 2011.

[53] Ubalua A. Cassava wastes: treatment options and value addition alternatives. African Journal of Biotechnology 2007;6(18):2065-73.

[54] Pattiya A. Bio-oil production via fast pyrolysis of biomass residues from cassava plants in a fluidised-bed reactor. Bioresource Technology 2010;102: 1959-67.

[55] Pattiya A. Thermochemical characterization of agricultural wastes from Thai cassava plantations. Energy Sources, Part A: Recovery, Utilization and Environmental Effects 2011;33:691-701.

[56] Serpagli A, Nagori G, Amoriggi G, Calvosa C. The use of cassava wastes to produce energy: Outcomes of a feasibility study implemented in Ghana. Tech. rep. Rome, Italy: IFAD; 2010.

[57] Stassen H. Small-scale biomass gasifiers for heat and power a global review. World Bank Technical Paper 296. Washington DC, USA: UNDP; 1995.

[58] Hamelinck C, Suurs R, Faaij A. International bioenergy transport costs and energy balance. Tech, rep. Utrecht, The Netherlands: Universiteit Utrecht, Copernicus Institute, Science Technology Society: 2003.

[59] Merino J. Electric energy efficiency. Tech. rep., In: Electricity transport and distribution, vol. 3. Madrid, Spain: CADEM-IBERDROLA; 2003.

[60] Hamelinck C, Faaij A. Future propects for production of methanol and hydrogen from biomass. Journal of Power Sources 2002;111:1-22.

[61] Trama Tecnoambiental (TTA). Estudio de base y definición de proyectos piloto para un programa nacional de electrificación rural en Paraguay. Tech. rep. Washington/Paraguay: Inter-American Development Bank/USA - Asunción; 2008.

[62] Ecoinvent Centre. The Ecoinvent database. V2.0, Tech. rep., St. Gallen, Switzerland: Swiss Centre for Life Cycle Inventories; 2008. 
[63] PRè-Consultants. Simapro 7.1.6. Tech. rep., Amersfoort, The Netherlands: PRèConsultants; 2008

[64] Bank of Ghana, website: http://www.bog.gov.gh/, Accessed August, 2011

[65] Vallvè X, González S, Arranz-Piera P. Solar-diesel hybrid options for the Peruvian Amazon - Lessons learnt from Padre Cocha. Tech. rep.,
Washington DC, USA: Energy Sector Management Assistance Program (ESMAP); 2007.

[66] International Electrotechnical Commission, IEC. Recommendations for small renewable energy and hybrid systems for rural electrification - Part 9-2: microgrids. Tech. rep., Geneva, Switzerland: IEC; 2006. 